\title{
Petrophysical properties of greensand as predicted from NMR measurements
}

\author{
Hossain, Zakir; Grattoni, Carlos A.; Solymar, Mikael; Fabricius, Ida Lykke
}

Published in:

Petroleum Geoscience

Link to article, DOI:

10.1144/1354-079309-038

Publication date:

2011

Link back to DTU Orbit

Citation (APA):

Hossain, Z., Grattoni, C. A., Solymar, M., \& Fabricius, I. L. (2011). Petrophysical properties of greensand as predicted from NMR measurements. Petroleum Geoscience, 17(2), 111-125. https://doi.org/10.1144/1354079309-038

\section{General rights}

Copyright and moral rights for the publications made accessible in the public portal are retained by the authors and/or other copyright owners and it is a condition of accessing publications that users recognise and abide by the legal requirements associated with these rights.

- Users may download and print one copy of any publication from the public portal for the purpose of private study or research.

- You may not further distribute the material or use it for any profit-making activity or commercial gain

- You may freely distribute the URL identifying the publication in the public portal

If you believe that this document breaches copyright please contact us providing details, and we will remove access to the work immediately and investigate your claim. 
3 Zakir Hossain* $^{*}$, Carlos A. Grattoni ${ }^{2}$, Mikael Solymar ${ }^{3}$ and Ida L. Fabricius ${ }^{1}$

4

$6 \quad{ }^{1}$ Department of Environmental Engineering

7 Technical University of Denmark,

8 Miljøvej, Building 113, DK-2800 Lyngby, Denmark.

9 zaho@env.dtu.dk (Zakir Hossain), ilfa@env.dtu.dk (Ida L. Fabricius)

$11{ }^{2}$ Rock Deformation Research Ltd, School of Earth and Environment

12 University of Leeds, Leeds LS2 9JT, UK, c.a.grattoni@leeds.ac.uk

13

14 35tatoil ASA, Oslo, Norway, miso@StatoilHydro.com

15

16 *Corresponding author (e-mail: zaho@env.dtu.dk)

17

18 Number of words of text: 7634

$19 \quad$ Number of references: $\quad 36$

20 Number of tables: $\quad 2$

21 Number of figures: 13

22 
Hossain et al. Petrophysical properties of greensand as predicted from NMR

\section{Abstract}

25 Nuclear magnetic resonance (NMR) is a useful tool in reservoir evaluation. The objective

26 of this study is to predict petrophysical properties from NMR $\mathrm{T}_{2}$ distributions. A series of

27 laboratory experiments including core analysis, capillary pressure measurements, NMR

$28 \mathrm{~T}_{2}$ measurements and image analysis were done on sixteen greensand samples from two

29 formations in the Nini field of the North Sea. Hermod Formation is weakly cemented,

30 whereas Ty Formation is characterized by microcrystalline quartz cement. The surface

31 area measured by BET method and the NMR derived surface relaxivity are associated

32 with the micro-porous glauconite grains. The effective specific surface area as calculated

33 from Kozeny’s equation and as derived from petrographic image analysis of

34 Backscattered Electron Micrograph's (BSE), as well as the estimated effective surface

35 relaxivity is associated with macro-pores. Permeability may be predicted from NMR by

36 using Kozeny’s equation when surface relaxivity is known. Capillary pressure drainage

37 curves may be predicted from NMR $\mathrm{T}_{2}$ distribution when pore size distribution within a

38 sample is homogeneous.

39

40 Keywords: Greensand, glauconite, porosity, permeability, capillary pressure, NMR 
Hossain et al. Petrophysical properties of greensand as predicted from NMR

41 Greensands are glauconite bearing sandstones composed of a mixture of stiff clastic

42 quartz grains and soft glauconite grains. Glauconite grains are porous and composed of

43 aggregates of iron-bearing smectitic or illitic clay. Porosity is thus found at two scales:

44 macro-porosity between grains and micro-porosity within grains (Fig. 1). Greensand

45 petroleum reservoirs occur world-wide, e.g. the mid-Cretaceous Safaniya Sandstone

46 Member in Saudi Arabia (Cagatay et al. 1996), the Cretaceous Mardi Greensand in

47 Australia (Hocking et al. 1988), the Lower Cretaceous Glauconitic sandstone in Alberta,

48 Canada (Tilley \& Longstaffe 1984), the Upper Cretaceous Shannon sandstone in

49 Wyoming, USA (Ranganathan \& Tye 1986), a lower Cretaceous Greensand offshore

50 Ireland (Winn 1994) and a late Paleocene Greensand in central part of the North Sea

51 (Slot-Petersen et al. 1998). However, evaluation of greensand reservoirs has challenged

52 geologists, engineers and petrophysicsts. Glauconite has an effect on porosity,

53 permeability and elastic properties of reservoir rocks (Diaz et al. 2003). Glauconite is

54 also ductile (Ranganathan \& Tye 1986) so it can cause non-elastic deformation of

55 greensand (Hossain et al. 2009) and affect the reservoir quality. Greensands generally

56 show low resistivity in the reservoir zone due to the large amount of bound water in the

57 glauconite, yet free hydrocarbons can be produced because glauconite rather than being

58 pore-filling is part of the sand grain framework (Slot-Petersen et al. 1998). Core analysis

59 of greensand thus shows a poor relationship between porosity and permeability.

60 Furthermore, greensand paramagnetic glauconite or pore filling berthierine may induce

61 magnetic gradients on the pore level causing the $\mathrm{NMR} \mathrm{T}_{2}$ relaxation time to be shortened

62 dramatically (Rueslåtten et al. 1998). 
Hossain et al. Petrophysical properties of greensand as predicted from NMR

63 Nuclear Magnetic Resonance (NMR) is a non-invasive technique, and NMR

64 measurements on reservoir core samples are done to obtain an improved interpretation of

65 logging data. NMR measures the net magnetization of a hydrogen atom $\left({ }^{1} \mathrm{H}\right)$ in the

66 presence of an external magnetic field. Hydrogen has a relatively large magnetic moment

67 and is abundant in both water and hydrocarbons in the pore space of a sedimentary rock.

68 NMR spectrometry involves a series of manipulations of the hydrogen protons found in

69 fluids. A measurement sequence starts with proton alignment to a magnetic field followed

70 by spin tipping, and decay. The quantities measured include signal amplitude which is

71 proportional to the number of hydrogen nuclei and decay, also called relaxation time

72 (Kenyon et al. 1995). Longitudinal relaxation time $\left(\mathrm{T}_{1}\right)$ measures the decay of spin

73 alignment; transverse relaxation time $\left(\mathrm{T}_{2}\right)$ measures the decay of precession. Although $\mathrm{T}_{1}$

74 measurements are more common in the literature, they are more time consuming than $\mathrm{T}_{2}$

75 measurements. Hence, pulsed NMR logging tools preferentially measure $\mathrm{T}_{2}$ for faster

76 logging speeds (Straley et al. 1997). NMR transverse relaxation $\left(\mathrm{T}_{2}\right)$ of fluids confined in

77 a porous rock is affected by pore surface, by the bulk relaxation process in the fluid and

78 additionally by dephasing in case of molecular diffusion. $\mathrm{T}_{2}$ may be expressed by the

79 fundamental equation governing the NMR relaxation spectrum (Coates et al. 1999):

80

81

$$
\frac{1}{T_{2}}=\frac{1}{T_{\text {2Surface }}}+\frac{1}{T_{2 \text { Bulk }}}+\frac{1}{T_{2 \text { Diffusion }}}
$$

82

83 Surface relaxation ( $T_{2 \text { Surface }}$ ) is the dominating mechanism in porous media, controlled by

84 pore surface area. The relation between NMR relaxation and pore surface area results 
Hossain et al. Petrophysical properties of greensand as predicted from NMR

85 from strong interaction between the protons and the surface because the surface

86 relaxivity $(\rho)$ causes rapid alignment of hydrogen protons on the pore wall, perhaps only

87 a monolayer or two thick, while protons in the remaining fluid decay through itself (bulk

88 relaxation), which is much slower (Howard et al. 1993). Bulk relaxation $\left(T_{2 B u l k}\right)$ is thus

89 significantly smaller than the surface relaxation and so where relaxation of diffusion

$90 \quad\left(T_{2 D i f f u s i o n}\right)$ is slow, the relaxation $\left(\frac{1}{T_{2}}\right)$ may be related to surface relaxivity and surface to

91 volume ratio of pores $(S p)$ :

92

93

$$
\frac{1}{T_{2}}=\rho_{2} S_{P}
$$

95 NMR measurements provide information about the pore structure ( $\mathrm{Sp}$ ), the amount of

96 fluid in-situ and interactions between the pore fluids and surface of pores. Thus,

97 laboratory NMR measurements can be used to obtain porosity and correlate pore size

98 distribution, clay bound water, and to estimate permeability and potentially predict

99 capillary pressure curves from longitudinal relaxation time $\left(\mathrm{T}_{1}\right)$ and transverse relaxation

100 time $\left(\mathrm{T}_{2}\right)$ distribution (Kenyon 1997). Numerous authors have explored the link between

101 NMR measurements and petrophysical properties, e.g. the wettability investigation by

102 NMR measurements by Al-Mahrooqi et al. (2003, 2006).

103

104 Porosity is one of the key parameter for hydrocarbon reservoir evaluation, and NMR is an

105 effective tool to determine the porosity. However, several authors reported that there exist 
Hossain et al. Petrophysical properties of greensand as predicted from NMR

106 significant differences between NMR porosity and core analysis porosity. Factors

107 influencing the $T_{2}$ measurements include paramagnetic minerals in the reservoir rock

108 which may cause $T_{2 \text { Diffusion }}$ and hence reduce the $T_{2}$ relaxation time (Xie et al. 2008).

109 Aditionally, iron and other paramagnetic minerals affect the surface relaxivity and

110 produce a shift of the relaxation distribution to shorter times (Dodge et al. 1995).

111 Rueslåtten et al. (1998) studied NMR of iron-rich sandstone from the North Sea and

112 found a detrimental effect of iron bearing minerals on porosity estimation by NMR $\mathrm{T}_{2}$.

114 Specific surface area is another significant petrophysical parameter for understanding the 115 physics of porous media and for permeability prediction. It was never fully integrated

116 into standard or special core analysis programs due to lack of petrophysical

117 understanding and concepts for correct evaluation (Riepe 1998). Nitrogen adsorption

118 methods (BET) yield high specific surface value as nitrogen enters the pores in the

119 sample. By using image analysis to determine the specific surface area, usually a much

120 smaller value is derived, and the value depends upon the resolution (Solymar et al. 2003).

121 The results of different methods reflect the different properties of pores at different

122 scales. By using a high resolution BET surface or a highly smoothed surface derived from

123 image analysis, the calculated permeability can be varied several orders of magnitude

124 (Riepe 1998). This is a concern because specific surface plays a vital role in

125 understanding and calibrating the $T_{2}$ spectra by estimating surface relaxivity (equation

126 (2)).

127 
Hossain et al. Petrophysical properties of greensand as predicted from NMR

128 NMR relaxation is thus not only affected by the pore dimensions but also by the

129 relaxivity of the rock surface. Quantitative knowledge of the surface relaxivity is needed

130 when $T_{2}$ distributions are interpreted. Surface relaxivity is required in order to convert $\mathrm{T}_{2}$

131 distribution into specific surface area, to calculate permeability and to convert $\mathrm{T}_{2}$ time to

132 capillary pressure curves. However, to measure surface relaxivity directly is not easy.

133 Surface relaxivity may be estimated by scaling the normalized capillary pressure curve to

134 the normalized $\mathrm{T}_{2}$ distribution (Kleinberg 1996); or by comparing NMR $\mathrm{T}_{2}$ distributions

135 to specific surface area from nitrogen BET adsorption (Hidajat et al. 2002). Alternatively,

136 it can be estimated by comparing NMR pore size distribution to pore size distribution

137 from image analysis of thin sections (Howard et al. 1993; Kenyon 1997). Kleinberg

138 (1996) concluded that the NMR effective specific surface area is closely associated with

139 hydraulic radius of the sedimentary rock and calculated effective surface relaxivity from

140 capillary pressure curves and $\mathrm{T}_{2}$ distribution.

142 Permeability is a difficult property to determine from logging data, yet it is essential for

143 reservoir characterization. Laboratory measurements provide absolute permeability at

144 core scale which could be different from reservoir permeability. NMR is the only tool

145 that attempts to estimate in-situ formation permeability (Hidajat et al. 2002; Glover et al.

146 2006). One of the most popular NMR derived permeability correlations is the Timur-

147 Coates formula (Coates et al. 1999), and is implemented as: 


$$
k_{N M R}=(C \phi)^{m}\left(\frac{F F I}{B F I}\right)^{n}
$$

151 where, $\phi$ is the porosity, $F F I$ is the free fluid volume and $B F I$ is the bound irreducible

152 fluid, as determined from NMR measurements. Formation dependent constants $C, m$ and

$153 n$ may be assumed to be 10,4 and 2 for sandstones respectively, where NMR

154 permeability, $k_{N M R}$ is given in $\mathrm{mD}$. However, this equation is simply an empirical derived

155 relationship that links various NMR-derived parameters to permeability. Especially for

156 diagenetically altered consolidated reservoir rocks, the complicated internal pore

157 structures may not be described by this model, causing unrealistic permeability estimates,

158 unless empirically calibrated parameters are used, which have no general physical

159 meaning and thus are only valid for special facies types and for local investigations.

160 Timur-Coates formula also indicates that porosity or pore volume strongly controls the

161 permeability together with the effective specific surface area as expressed by $\frac{F F I}{B F I}$ in

162 accordance with the equation of Kozeny (1927). For homogeneous sediments like chalk,

163 the effective specific surface is equivalent to the one measured by nitrogen adsorption

164 (BET) and Kozeny's equation works well without introducing empirical factors

165 (Mortensen et al. 1998). However, for less homogenous sediments, like greensand, we

166 can calculate an effective surface area (Sp(Kozeny)) from permeability and porosity by

167 using Kozeny's equation. We infer that it is this effective surface that controls

168 permeability. 
Hossain et al. Petrophysical properties of greensand as predicted from NMR

170 Capillary pressure $\left(\mathrm{P}_{\mathrm{c}}\right)$ curves can be determined only from core analysis, but NMR

171 derived $\mathrm{P}_{\mathrm{c}}$ curves provide a fast, cheap and non-destructive estimation. However, up to

172 now, most authors have focused on the relation between $\mathrm{T}_{2}$ distribution and $\mathrm{P}_{\mathrm{c}}$ curves

173 (Kleinberg 1996; Grattoni et al. 2003; Marschall et al. 1995; Volokitin et al. 1999) and

174 the general conclusion is that, if the bulk relaxation and diffusion effects are ignored, a

175 simple relationship between $\mathrm{P}_{\mathrm{c}}$ and $\mathrm{T}_{2}$ becomes:

176

$$
P_{c}=\frac{K}{T_{2}}
$$

179 where, $\mathrm{K}$ is an empirical scaling factor introduced to predict capillary pressure curves.

180 However, several authors, e.g. Kleinberg (1996) concluded that the match between

181 capillary pressure and NMR relaxation curves are not universal. The simple relationship

182 (equation (4)) reflects that both the $\mathrm{T}_{2}$ distribution and $\mathrm{P}_{\mathrm{c}}$ curves are affected by pore

183 structures but overlooks the difference between the physics of the processes. Kewan \&

184 Ning (2008) discussed that in a pore and throat model of the pore space, the capillary

185 pressure is sensitive to the pore throat, whereas the NMR measures the pore body size.

186 Thus, the technique gives same information only when there is a constant ratio between

187 them.

189 The combination of conventional core analysis, such as Helium porosity, Gas

190 permeability, specific surface area by BET and image analysis of thin sections

191 micrographs is proven to be very effective in the evaluation of normal reservoir rocks. 
Hossain et al. Petrophysical properties of greensand as predicted from NMR

192 However, for glauconite bearing greensand where a high proportion of micro-porosity in

193 glauconite grains creates an uncertainty with respect to fluid distribution and fluid

194 saturation, an accurate determination of petrophysical properties by using conventional

195 core analysis is difficult (Rueslåtten et al. 1998). The objective of this study is to predict

196 petrophysical properties from NMR $\mathrm{T}_{2}$ distributions which can be applied to in-situ well

197 logging. Estimates of porosity, permeability, irreducible water saturation derived from

198 NMR measurement were corrected with measurements from core analysis. The porosity

199 obtained by using the different methods was compared for the greensand samples. The

200 potential use of surface area data is also described and illustrated. Kozeny's equation was

201 used for NMR permeability prediction and $\mathrm{P}_{\mathrm{c}}$ curves were estimated from NMR

202 measurements.

203

204 Geological setting of Nini Field

206 The Nini field is located in Siri Canyon which is part of a larger system of submarine

207 canyons in the Paleocene in the Norwegian-Danish Basin running in an E-W to NE-SW

208 direction towards the Central Graben (Fig. 2) (Stokkendal et al. 2009). The Nini

209 accumulation is defined by a combined structural and stratigraphic trap, the anticlinal

210 structure being induced through salt tectonics. The reservoir consists of sands deposited

211 in the Siri Fairway (Schiøler et al. 2007).

212

213 The glauconite bearing sandstone in the Nini field was recognized by stratigraphic work

214 in Statoil in the mid-1990s (Schiøler et al. 2007). It is formally included in the Hermod 
Hossain et al. Petrophysical properties of greensand as predicted from NMR

215 Formation and in the older Ty Formation. These Paleocene reservoir sands are

216 characterized by glauconite rich (20-30 vol \%) fine grained, well sorted sand, embedded

217 in hemiplegic to pelagic mud- and marl-stones, in which both quartz grains and

218 glauconite pellets are part of the load-bearing matrix. The greensand beds thus occur in a

219 shale-sequence. In the Nini wells, the Hermod sand was found to be more massive, more

220 porous and more permeable than Ty sand (Fig. 3).

221

222 Method

223

224 We studied sixteen one and half inch horizontal core plugs from the two greensand

225 formations of the Nini-1 well (7 samples from Hermod Formation and 9 samples from Ty

226 Formation). The samples had already been used for routine core analysis and were chosen

227 so as to cover the range of variation in porosity (25\%-40\%) and air permeability (60 mD-

$2281000 \mathrm{mD}$ ). All cores were cleaned from brine and hydrocarbons by soxhlet extraction

229 with methanol and toluene prior to analysis. Thin sections were prepared from the end of

230 each plug and material from the end trimmings were used for X-ray diffraction (XRD)

231 and BET analysis.

232

233 Routine core analysis

234

235 Helium porosity $\left(\phi_{H}\right)$ of the samples was measured by the gas expansion method. Helium

236 porosity is a good measure of total porosity, including porosity in clay minerals, as no

237 pores are so small that Helium cannot enter. Buoyancy of the cores in brine (Archimedes) 
Hossain et al. Petrophysical properties of greensand as predicted from NMR

238 was also used to determine bulk volume on a fully saturated sample and pore volume was

239 calculated from grain density as measured by the gas expansion method. Complete

240 saturation was verified by comparing porosity measured by Helium expansion and by

241 Archimedes method. As porosity data from the two methods are within experimental

242 error, all samples were assumed to be fully brine saturated.

243

244 Klinkenberg corrected permeability was derived from permeability at a series of nitrogen

245 gas pressures. Specific surface area of the grain $\left(S_{g}\right)$ was measured by BET method by

246 using nitrogen gas adsorption. Specific surface of pores from BET method $(S p(B E T))$ was

247 calculated by dividing $S_{g}$ by porous fraction, $\left(\phi_{H}\right)$ and multiplying by grain fraction, $\left(1-\phi_{H}\right)$

248 as:

$$
S p(B E T)=S_{g}\left(\frac{1-\phi_{H}}{\phi_{H}}\right) \rho_{g}
$$

250

251 where, $\rho_{g}$ is grain density.

252 The effective bulk specific surface $(S)$ was obtained from Klinkenberg permeability $(k)$

253 and macro-porosity ( $\phi$ ) by using Kozeny’s equation (Kozeny 1927) as:

254

255

$$
k=c \frac{\phi^{3}}{S^{2}}
$$

257 where, $c$ is Kozeny’s factor which can be estimated from porosity via a simple model of

258 linear 3D interpenetrating tubes (Mortensen et al. 1998):

259 


$$
c=\left[4 \cos \left\{\frac{1}{3} \arccos \left(\phi \frac{8^{2}}{\pi^{2}}-1\right)+\frac{4}{3} \pi\right\}+4\right]^{-1}
$$

262 According to equation (7), c increases from 0.15 to 0.25 as porosity increases from 0.05

263 to 0.5 . Specific surface of pores from Kozeny’s equation (Sp(Kozeny)) can then be

264 calculated:

265

$$
S p(\text { Kozeny })=\frac{S}{\phi}
$$

$266 \frac{1}{\text { Sp(Kozeny) }}$ is equivalent to hydraulic radius and thus should be related to capillary

267 pressure and $\mathrm{T}_{2}$ relaxation, so we base the remaining analysis on Sp(Kozeny).

\section{Capillary pressure}

271 The capillary pressure may be expressed by the fundamental equation:

$$
P_{c}=\frac{2 \sigma \cos \theta}{r_{c}}
$$

274 where, $r_{c}$ is the radius of pore throat, $\sigma$ is the surface tension and $\theta$ is the contact angle.

275 For water-wet conditions $\cos \theta$ becomes one, and in terms of specific surface of pore (Sp)

276 equation (9) may be rewritten as:

$$
P_{c}=S_{P} \sigma
$$


Hossain et al. Petrophysical properties of greensand as predicted from NMR

279 Air brine drainage capillary pressure measurements were done on brine saturated

280 greensand samples by using the porous plate method at room temperature. Initially each

281 sample was saturated with simulated formation brine. The brine has a density of 1.06

$282 \mathrm{~g} / \mathrm{cm}^{3}$ and a viscosity of $1.054 \mathrm{cP}$. Irreducible water saturation $\left(S_{w i}\right)$ including clay

283 bound water was determined from capillary pressure curves and macro-porosity was

284 calculated as porosity above irreducible water saturation (Fig. 4b).

285

286

287

288

289

Image analysis

290

291 Polished thin sections were prepared from all samples in a plane perpendicular to the

292 flow direction during core analysis. A Philips XL40 Scanning Electron Microscope was

293 used for acquisition of Back Scattered Electron (BSE) images. The images are $1024 \mathrm{x}$

2941024 byte greyscale images with a pixel length of $1.78 \mu \mathrm{m}$. This magnification resolves

295 the intergranular macro-porosity and leaves the micro-porosity unresolved. Each image

296 was filtered to remove the noise and thresholded to create a binary image prior to

297 analysis. Porosity determined in the images is called image porosity ( $\left.\phi_{\text {image }}\right)$. The image

298 analysis procedure is sensitive to porosity threshold, so image porosity was determined when

299 they are equal to macro-porosity determined from $\mathrm{P}_{\mathrm{C}}$ measurements. The macro-porosity

300 determined by image analysis is within a narrow range ( \pm 2.5 p.u.) obtained by image analysis 
301 along. The specific surface area or strictly speaking the specific perimeter (S(image)) of

302 the solid grains was determined by using the method of Borre et al. (1995). According to

303 Underwood (1970) and Solymar \& Fabricius (1999) the specific perimeter (S( image)) may

304 be approximated to the 3-D specific surface (S) by:

305

306

$$
S=\frac{4}{\pi} S(\text { image })
$$

307

308 Image specific surface of pores ( $S_{p}$ (image)) is thus calculated by using equation (8) where

309 porosity is defined as macro-porosity determined from capillary pressure measurements.

\section{$311 \quad$ NMR measurements}

313 For NMR measurements all samples were saturated with brine (7.6\% $\mathrm{NaCl})$. Complete

314 saturation was verified by using the dry weight, the saturated weight, grain volume by

315 Helium expansion, and brine density. All samples attained full brine saturation. All the

316 measurements were performed with the samples sleeved in PTFE heat shrink as several

317 were poorly consolidated. The weights and volumes of the heat shrink material were

318 accounted for in the measurements.

320 The laboratory NMR measurements were performed using a Resonance Instruments

321 MARAN 2 spectrometer at ambient pressure and $34^{\circ} \mathrm{C}$ at a proton resonance frequency of

322 2.2 MHz. T2 relaxations was measured using Carr-Purcel-Meiboom-Gill (CPMG) pulse 
Hossain et al. Petrophysical properties of greensand as predicted from NMR

323 sequence. The $\mathrm{T}_{2}$ relaxation curves were measured by using a Recycle Delay (Repetition

324 Time) of $10 \mathrm{sec}$, Number of Echos 8000, CPMG inter echo spacing $(\tau) 200 \mu$ s and 100

325 scans. The $\pi / 2$ and $\pi$ pulses were $14.8 \mu$ s and $29.6 \mu$ s, respectively.

326

327 NMR porosity of the fully saturated samples was determined by using the total signal 328 amplitude of each sample (by summing the amplitudes of the T2 distribution) and known

329 standard of similar diameter. In this case the reference standard was a sealed glass vial,

330 containing $3 \mathrm{~cm}^{3}$ of $50,000 \mathrm{ppm} \mathrm{NaCl}$ and $17 \mathrm{~cm}^{3}$ of deuterium oxide. Deuterium oxide

331 does not have an NMR signal therefore this reference standard has an equivalent porosity

332 of $15 \%$. The same number of scans was used for the reference and the sample. NMR

333 porosity is then calculated using the, total signal amplitude, the bulk volume, hydrogen

334 index of both plug and reference and the equivalent porosity of the reference.

336 For determining the macro-porosity and micro-porosity we need a cutoff value from the

$337 \mathrm{~T}_{2}$ distribution. For two samples (one from Hermod and one from Ty), the $\mathrm{T}_{2}$ cutoff was

338 determined in the laboratory by obtaining the $\mathrm{T}_{2}$ distribution at two saturations, fully

339 brine saturated and at irreducible water saturation as determined from capillary pressure

340 curves. The analysis of the air-water systems is relatively easy as there is no NMR

341 response from the air and the relaxation time is exclusively due to the protons in the

342 water. The cutoff time is defined as the relaxation time at the point where the cumulative

343 porosity of the fully saturated sample equals the irreducible water saturation (Fig. 4a). As

344 the $\mathrm{T}_{2}$ cutoff is determined from capillary pressure equilibrium experiments includes

345 capillary bound fluid and trapped in micro-pores. A single $\mathrm{T}_{2}$ cutoff value for each 
346 formation was used for all samples of that formation. The cumulative porosity over the

347 range $\mathrm{T}_{2}>\mathrm{T}_{2 \text { cutoff }}$ was the macro-porosity and below the range $\mathrm{T}_{2}<\mathrm{T}_{2 \text { cutoff }}$ was the micro-

348 porosity or irreducible water saturation.

349

350 The NMR permeability model used in this work was obtained by combining equation (2),

351 (6), and (8):

352

353

$$
k=c \phi\left(T_{2} \rho_{2}\right)^{2}
$$

354

355 In a similar way the capillary pressure NMR model was obtained combining equation (2)

356 and (10):

$$
P_{c}=\frac{\sigma}{\rho_{2} T_{2}}
$$

358 The assumption of this model is that: 1- the pore structure controlling the T2 distribution

359 and capillary pressure is a bundle of capillary tubes and the drainage is controlled by the

360 hierarchy of pore sizes; 2- the surface relaxivity is constant overall the sample; 3-

361 diffusion relaxation is negligible.

362

\section{Results}

364

365 The Helium porosity of greensand ranges from 28 to 42 p.u. (porosity units) with a 366 maximum uncertainty 1.5 p.u. (Table 1). Klinkenberg corrected permeability ranges from 
Hossain et al. Petrophysical properties of greensand as predicted from NMR

36760 to $940 \mathrm{mD}$ (Table 2). Permeabilities of Hermod samples are larger than Ty samples

368 and correlates with porosity, whereas Ty data are more scattered (Fig. 5).

369

370 Petrographic thin section analysis indicates that the studied Paleocene greensands are

371 well to very well sorted, dominated by grains of quartz but also large volumes of

372 glauconite (20-25 vol \%) (Fig. 6). Samples from Hermod Formation contain glauconite

373 grains of size between 100 and $200 \mu \mathrm{m}$, some glauconite grains are larger (300 to 400

$374 \mu \mathrm{m})$ (Fig. 1a). Samples from Ty Formation contain glauconite grains of size between 100

375 and $150 \mu \mathrm{m}$, although some glauconite grains are larger (200 to $300 \mu \mathrm{m})$ (Fig. 1b). The

376 grains are subangular to sub-rounded for the both Formations. Hermod Formation is only

377 weakly cemented, whereas samples from Ty formation contain cement of berthierine or

378 microcrystalline quartz cement resulting in relative in a low permeability (Table 2). In

379 both formations XRD analyses of separated glauconite grains show the presence of some

380 expanding layers in the predominantly illitic glauconite.

381

382 The capillary pressure was obtained assuming $72 \mathrm{mN} / \mathrm{m}$ for the brine surface tension.

383 Capillary pressure curves show that for the higher permeability Hermod Formation

384 samples, the $\mathrm{P}_{\mathrm{c}}$ curves are shifted toward low irreducible water saturation, whereas $\mathrm{P}_{\mathrm{c}}$

385 curves for the lower permeability Ty Formation samples are shifted toward high

386 irreducible water saturation (Figs 7a, c). Irreducible water saturation from capillary

387 pressure was obtained at $\mathrm{P}_{\mathrm{c}} 100$ psi, and varied between $25 \%$ and $42 \%$ of the total

388 porosity (Table 2). 
Hossain et al. Petrophysical properties of greensand as predicted from NMR

390 The NMR $\mathrm{T}_{2}$ distributions are presented in graphical form for each sample and the

391 population is expressed in porosity units in Figures 7b, d. All $T_{2}$ distributions are

392 bimodal. Each $\mathrm{T}_{2}$ time corresponds to a particular pore size. If the rock has a single pore

393 size then instead of a broader distribution there will be a single vertical line. Thus broader

394 distributions reflect greater variability in pore size. We have determined a time cutoff of

$3955.21 \mathrm{~ms}$ for the sample 1-4 from Hermod Formation and $3.68 \mathrm{~ms}$ for sample 1A-141 from

396 the Ty Formation. The short relaxation time component in a $T_{2}$ distribution of a rock is

397 attributed to the water in glauconite. For the present greensand samples a peak close to 1

398 ms should correspond to glauconite water, whereas all samples also present a second

399 peak close to 100 ms that corresponds to movable fluid. Higher permeability Hermod

400 Formation samples show larger amplitude in the movable fluid than samples from Ty

401 Formation; whereas lower permeability bearing Ty Formation sample show slightly

402 larger amplitude in capillary bound and glauconite water (Figs 7b, d).

404 Discussion

405 Porosity

407 Helium porosity, Archimedes porosity and NMR porosity are compared in Figure 8.

408 Helium porosity is associated with the total porosity of the sample including micro-

409 porosity in glauconitic and it shows the highest values among the three types of porosity

410 data. However, Archimedes and NMR porosity should also in principle represent the total

411 porosity of a sample, but could be lower if water saturation is below $100 \%$. Although the 
Hossain et al. Petrophysical properties of greensand as predicted from NMR

412 Archimedes porosity is close to Helium porosity, NMR porosity tends to be lower. Both

413 macro-porosity and micro-porosity are underestimated by the NMR measurements (Figs

414 8c, d). The discrepancy between Archimedes porosity and NMR porosity could be due to

415 several factors. First, NMR and Archimedes porosity depend on saturation condition of

416 the sample. So we cannot rule out that during NMR measurement the saturation condition

417 was lower than that at the Archimedes measurements. Second, paramagnetic iron-bearing

418 minerals in reservoir rock may be an important factor influencing $\mathrm{T}_{2}$ measurements as

419 shown by Dodge et al. (1995). The presence of paramagnetic ions increases the rate of

420 relaxation of the hydrogen proton. This is expected for greensand because glauconite and

421 berthierine are iron-bearing. These clay minerals have large surface area and high

422 magnetic susceptibilities leading to large internal gradients and short $\mathrm{T}_{2}$ (Straley et al.

423 1997). Rueslåtten et al. (1998) illustrated the influence of chlorite (berthierine) and

424 glauconite on the difference between Helium porosity and NMR $\mathrm{T}_{2}$ derived porosity

425 (delta porosity) and found broad positive correlation between delta porosity and chlorite

426 content, whereas they found no correlation with glauconite content. Thus they pointed to

427 the detrimental effect of chlorite or berthierine on porosity estimated by NMR. However,

428 we found only a vague negative correlation between delta porosity and bulk mineral

429 composition (glauconite, clay coating and pores filling) (Fig. 8b).

430

431 Specific surface area

432

433 Specific surface area with respect to pore (Sp), determined by three methods are

434 compared in Figure 10a. We found a large difference between the specific surface areas 
Hossain et al. Petrophysical properties of greensand as predicted from NMR

435 as measured by BET method (Sp(BET), 76-141 $\mu^{-1}$ ) and calculated by Kozeny’s

436 equation (Sp(Kozeny), 0.27-0.95 $\mu^{-1}$ ) and determined by image analysis (Sp(image),

$437 \quad 0.32-0.46 \mu \mathrm{m}^{-1}$ ). Nitrogen adsorption has a very high resolution; therefore this method

438 determines the specific surface of the total porosity, including micro-porosity. Based on

439 the Kozeny's equation, we estimated Sp(Kozeny) by using permeability determined on

440 the cores and macro-porosity. Sp by image analysis depends on the resolution of the

441 image (Solymar et al. 2003). However, Sp from image analysis at the present pixel size

442 and Sp from Kozeny’s equation are in same order of magnitude which tells us that

443 resolution of image is sufficient and pixel size is small enough to determine Sp by image

444 analysis. The specific surface area of separated glauconite grains are in order of 1300-

$4451600 \mu^{-1}$, whereas the specific surface area of quartz grains is less than $1 \mu^{-1}$. So

446 rather than quartz grains, specific surface of glauconite grains are measured by BET

447 method. Thus, Sp by BET method is mainly reflected by the micro-pores of glauconite

448 grains and pore filling/lining clays, whereas Sp from Kozeny’s equation and image

449 analysis is associated with effective surface and related to macro-porosity. We found that

450 Sp measured by BET method is well correlated with fraction of glauconite plus pore

451 filling clay minerals (Fig. 9c).

452

453 We found that irreducible water saturation ranges from $22 \%$ to $41 \%$ from capillary

454 pressure measurements and from 23\% to 36\% from NMR measurements. Considering

455 errors association with these two methods, irreducible water saturations are close to each

456 other. The high value of irreducible water saturation is due to the high specific surface of

457 glauconite. The micro-pores of glauconite remain brine filled even at a capillary pressure 
Hossain et al. Petrophysical properties of greensand as predicted from NMR

458 of 100 psi. We found a positive correlation between irreducible water saturation

459 determined from $\mathrm{P}_{\mathrm{c}}$ and NMR with Sp determined from BET method (Figs 9a, b). In

460 addition Figures 9a, b also show the tendency for low surface area samples to approach

461 minimum irreducible water saturation and for high surface area samples to remain more

462 saturated. A relationship between specific surface and irreducible water saturation has

463 been noted by several authors e. g. Hamada et al. (2001) where authors reported an

464 excellent correlation $\left(\mathrm{R}^{2}=0.98\right)$ between irreducible water saturation and specific surface

465 of pores.

466

467 Surface relaxivity

468

469 We compare four ways of estimating surface relaxivity in Figure 10b. Equation (2) shows

470 that surface relaxivity for NMR $\mathrm{T}_{2}$ distribution is related to specific surface of pores.

471 Thus in absence of laboratory data, surface relaxivity may be evaluated by comparing $\mathrm{T}_{2}$

472 distributions with $S p(B E T)$, $S p$ (Kozeny) or $S p$ (image). This results in relaxivity value

473 ranges in order of 2.7-4.2 $\mu \mathrm{m} / \mathrm{s}$ from $S p(B E T), 7-58 \mu \mathrm{m} / \mathrm{s}$ from $S p$ (Kozeny), and 10-35

$474 \mu \mathrm{m} / \mathrm{s}$ from Sp(image). As an alternative, we used $\mathrm{P}_{\mathrm{c}}$ curves and found that a surface

475 relaxivity of $20.4 \mu \mathrm{m} / \mathrm{s}$ for Hermod and of $28.4 \mu \mathrm{m} / \mathrm{s}$ for Ty Formation are needed to

476 generate Pc curves from NMR measurements. The surface relaxivity estimated based on

$477 S p(B E T)$ would be controlled by micro-porosity in glauconite. We found an average

478 surface relaxivity by $S p(B E T)$ of $3.42 \mu \mathrm{m} / \mathrm{s}$, which is close to the $3.3 \mu \mathrm{m} / \mathrm{s}$ for glauconite

479 reported by Matteson et al. (1996). Surface relaxivity estimated from Sp(Kozeny) and 
Hossain et al. Petrophysical properties of greensand as predicted from NMR

480 Sp(image) also should be effective surface relaxivity as it was calculated from effective

481 specific surface area.

482

483 Permeability

484

485 Kozeny's equation (equation (12)) was used to predict permeability from NMR $\mathrm{T}_{2}$ 486 distributions. Before applying this equation we highlight the similarities and differences 487 within $\mathrm{T}_{2}$ distribution among samples (Fig. 11). The $\mathrm{T}_{2}$ distribution of sample 1-18 peaks 488 at longer time than for sample 1-6, thus the larger porosity of sample 1-18 is due to the 489 larger pores which also cause higher permeability (Fig. 11a). The comparison of three 490 samples with similar distributions at shorter times is shown in Figure 11b. When the 491 larger peak (around $100 \mathrm{~ms}$ ) becomes smaller and is shifted to larger times due to a small 492 number of intermediate pores, there is a small increase of the number of larger pores. 493 Thus, for these samples the permeability is not high although porosity is higher. We thus 494 cannot use average $T_{2}$ time or final $T_{2}$ time in equation (12) for permeability calculation. 495 So we modified the equation (12) by summing the total permeability among the $T_{2}$ 496 distribution and only including the macro-porosity. Thus resulting: 497

$$
k=c \phi \rho_{2}^{2} \sum_{i=1}^{N} f_{i}\left(T_{2 i}\right)^{2}
$$


Hossain et al. Petrophysical properties of greensand as predicted from NMR

500 where, $f i$ is a fraction of the total amplitude of each $T_{2 i}$. Kozeny factor c was calculated

501 using equation (7).

502

503 The predicted permeability distribution obtained by using equation (14) is shown in

504 Figures 11c, d. Below cutoff time, the amplitude of permeability is zero which means

505 micro-porosity does not contribute to fluid flow. From cutoff time to $100 \mathrm{~ms}$, the

506 amplitude of permeability is small but above $100 \mathrm{~ms}$ the contribution of permeability

507 increases.

508

509 Predicted permeability and measured permeability are compared in Figure12a by using

510 surface relaxivity from $\operatorname{Sp}$ (Kozeny) (Average surface relaxivity for each depth interval),

511 in Figure 12b by using surface relaxivity from Sp(image), in Figure 12c by using surface

512 relaxivity from equation (13), and in Figure12d by using surface relaxivity from $S p(B E T)$.

513 Predicted permeability is close to 1:1 line of measured permeability for case 1 and 2 . The

514 estimated permeability from Timur-Coates model is illustrated in Figure 12e. Predicted

515 permeability using this model works rather well if we use $C=8.3$ which was optimized in

516 a least-squares sense such that the sum of the squared error between the measured and

517 predicted permeability is minimized. Predicted permeability from image analysis and

518 measured permeability are compared in Figure 12f. Image permeability and NMR

519 predicted permeability by using surface relaxivity from Sp(image) are equal.

520

521 Capillary pressure curves

522 
Hossain et al. Petrophysical properties of greensand as predicted from NMR

523 We applied the value of surface relaxivity of $20.3 \mu \mathrm{m} / \mathrm{s}$ and $28.4 \mu \mathrm{m} / \mathrm{s}$ for Hermod

524 Formation and Ty Formation sample respectively to generate the capillary pressure

525 curves directly from the $T_{2}$ distribution by using equation 13 (Fig. 13). Capillary

526 pressure curves overlay each other for low permeability samples. However, we found

527 deviation between the $\mathrm{P}_{\mathrm{c}} \mathrm{NMR}$ and $\mathrm{P}_{\mathrm{c}}$ lab for the high permeability sample from Hermod

528 Formation. A deviation is to be expected, because we assumed uniform surface

529 relaxivity within a sample and ignored diffusion relaxation. The calculated surface

530 relaxivity is shown in Figure 13e for a sample from Hermod Formation and in Figure $13 \mathrm{f}$

531 for a sample from Ty Formation. A good match between $\mathrm{P}_{\mathrm{c}}$ curves from laboratory and

532 NMR measurement is found when average surface relaxivity is equal to surface relaxivity

533 applied to predict $\mathrm{P}_{c}$ curves from NMR. In contrast, we found deviation between $\mathrm{P}_{\mathrm{c}}$

534 curves from laboratory and NMR measurements when average surface relaxivity is not

535 equal to the surface relaxivity need to match Pc curves. This variation of surface

536 relaxivity within the sample is probably due to the large pores and higher permeability in

537 the greensands of Hermod Formation.

538

539 Conclusion

540

541 The objective of this study is to predict petrophysical properties from $\mathrm{NMR} \mathrm{T}_{2}$

542 distributions. Based on laboratory experiments and image analysis on sixteen greensand

543 samples from the two formations in the Nini field of the North Sea, we found Hermod

544 Formation is only weakly cemented, whereas samples from Ty formation contain cement 
Hossain et al. Petrophysical properties of greensand as predicted from NMR

545 of berthierine or microcrystalline quartz cement resulting in relatively to lower

546 permeability than Hermod samples.

548 We found that the total porosity measured by Archimedes method is to close to Helium

549 porosity, whereas NMR porosity tends to be lower. The discrepancy between Archimedes

550 porosity and NMR porosity may be due to a combination of several factors, including the

551 presence of glauconite grains in greensand.

552

553 This study shows that the surface area measured by BET method and the derived surface

554 relaxivity are associated with the micro-porous glauconite grains. The effective surface

555 area as calculated by Kozeny’s equation and as determined from petrographic image

556 analysis of Backscattered Electron Micrographs and the estimated effective surface

557 relaxivity is associated with macro-pores. We found that $S p$ measured by BET method is

558 well correlated with fraction of glauconite plus pore filling clay minerals.

560 Irreducible water saturation in the studied greensands ranges from $22 \%$ to $41 \%$ and these

561 high values are due to the high specific surface area of glauconite. The micro-pores of

562 glauconite remain brine filled even at a capillary pressure of 100 psi.

563

564 We found that predicted permeability from NMR by using Kozeny’s equation agrees well

565 when surface relaxivity is known. By using Timur-Coates model, predicting permeability

566 works rather well if we optimize the constant to $C=8.3$. 
568 This study shows that predicted capillary pressure curves from NMR $\mathrm{T}_{2}$ distribution

569 overlay on measured capillary pressure curves for low permeability samples. The

570 deviation between the $\mathrm{P}_{c}$ NMR and $\mathrm{P}_{c}$ lab for the high permeability samples is due to the

571 contrasting relaxivity on the surface of quartz and glauconite.

572 


\section{Acknowledgements}

574

575 Niels Springer and Hans Jørgen Lorentzen (GEUS, DK) are thanked for help with the

576 core analysis. Sinh Hy Nguyen (DTU, DK) performed XRD and BET measurements,

577 Hector Ampuero Diaz (DTU, DK) prepared polished thin sections. DONG Energy A/S is

578 acknowledged for financial support.

579

580 Appendix

581 Nomenclature

$582 \quad B F V \quad$ Bound fluid volume

$583 \quad C \quad$ Formation dependent constant

$584 \quad c \quad$ Kozeny factor

$585 f_{i} \quad$ Amplitude of each $\mathrm{T}_{2 \mathrm{i}}$

586 FFI Free fluid volume

$587 k \quad$ Klinkenberg permeability,

$588 \quad K \quad$ Scaling factor

$589 \quad S \quad$ Specific surface area of bulk

$590 S_{g} \quad$ Specific surface area of grains

$591 \quad S p \quad$ Specific surface of pores

$592 \quad T_{2 B u l k} \quad$ Relaxation of fluids

$593 T_{2 \text { Diffisionk }} \quad$ Relaxation of molecular diffusion

$594 \quad T_{2 \text { Surace }} \quad$ Relaxation of surface 
596 Greek symbols

$597 \phi \quad$ Porosity (fraction)

$598 \quad \rho \quad$ Surface relaxivity

$599 \tau \quad$ Inter echo spacing.

600

\section{Unit conversion}

602

$6031 \mathrm{mD}=0.986910^{-15} \mathrm{~m}^{2}$

$604 \quad 1 \mathrm{psi}=6.89 \mathrm{kPa}$

605 
Hossain et al. Petrophysical properties of greensand as predicted from NMR

\section{References}

607

608 Al-Mahrooqi, S. H., Grattoni, C. A., Muggeridge, A. H., Zimmerman, R. W. \& Jing, X.

609 D. 2006. Pore-scale modeling of NMR relaxation for the characterization of wettability.

610 Journal of Petroleum Science and Engineering, 52, 172-186.

611 Al-Mahrooqi, S. H., Grattoni, C. A., Moss, A. K. \& Jing, X. D. 2003. An investigation of

612 the effect of wettability on NMR characteristics of sandstone rock and fluid systems.

613 Journal of Petroleum Science and Engineering, 39, 389-398.

614 Borre, M., Lind, I. \& Mortensen, J. 1997. Specific surface as a measure of burial

615 diagenesis of chalk. Zentralblatt fur Geologie und Palaontologie, 1, 1071-1078.

616 Cagatay, M. N., Saner, S., Al-Saiyed, I. \& Carrigan, W. J. 1996. Diagenesis of the

617 Safaniya Sandstone Member (mid-Cretaceous) in Saudi Arabia. Sedimentary Geology,

618 105, 221-239.

619 Coates, G. R., Xiao, L., et al. 1999. NMR logging principles and applications. Gulf

620 Professional Publishing, Houston, Texas, 234.

621 Diaz, E., Prasad, M., Mavko, G. \& Dvorkin, J. 2003. Effect of glauconite on the elastic

622 properties, porosity, and permeability of reservoir rocks. The Leading Edge, 22, 42-45. 
Hossain et al. Petrophysical properties of greensand as predicted from NMR

623 Dodge, W. S., Shafer, J. L., Guzman-Garcia, A. G., \& Noble, D. A. 1995. Core and Log

624 NMR Measurements of an Iron-Rich, Glauconitic Sandstone Reservoir. $36^{\text {th }}$ Annual

625 Symposium of SPWLA, Paris, France, June 26-29.

626 Glover, P., Zadjali, I. \& Frew, K. 2006. Permeability prediction from MICP and NMR

627 data using an electrokinetic approach. Geophysics, 71, 49-60.

628 Grattoni, C. A., Al-Mahrooqi, S. H., Moss, A. K., Muggeridge, A. H. \& Jing, X. D. 2003.

629 An improved technique for deriving drainage capillary pressure from $\mathrm{NMR}_{2}$

630 distributions. The International Symposium of the Society of Core Analysis, 25, 21-24

631 September, Pau, France.

632 Hamada, G., Al-Blehed, M., Al-Awad, M. \& Al-Saddique, M. 2001. Petrophysical

633 evaluation of low-resistivity sandstone reservoirs with nuclear magnetic resonance log.

634 Journal of Petroleum Science and Engineering, 29, 129-138.

635 Hidajat, I., Singh, M., Cooper, J. \& Mohanty, K. K. 2002. Permeability of porous media

636 from simulated NMR response. Transport in Porous Media, 48, 225-247.

637 Hocking, R., Voon, J. \& Collins, L. 1988. Stratigraphy and sedimentology of the basal

638 Winning Group, northern Carnarvon Basin. In: P.G. Purcell and R.R. Purcell (editors),

639 The North West Shelf, Proceedings of Petroleum Exploration Society Australia

640 Symposium, Perth, 203-224.

641 Hossain, Z., Fabricius, I. L. \& Christensen, H. F. 2009. Elastic and nonelastic

642 deformation of greensand. The Leading Edge, 28, 260-262. 
Hossain et al. Petrophysical properties of greensand as predicted from NMR

643 Howard, J. J., Kenyon, W. E. \& Straley, C. 1993. Proton magnetic resonance and pore

644 size variations in reservoir sandstones. SPE Formation Evaluation, 1, 194-200.

645 Kenyon, B., Kleinberg, R., Straley, C. \& Morriss, C. 1995. Nuclear Magnetic Resonance

646 Imaging-Technology for the 21st Century. Oilfield Review, 7, 19-30.

647 Kenyon, W. E. 1997. Petrophysical principles of applications of NMR logging. The Log

648 Analyst, 38, 21-43.

649 Kewan, W. \& Ning, L. 2008. Numerical simulation of rock pore-throat structure effects

650 on NMR T2 distribution. Applied Geophysics, 5, 86-91.

651 Kleinberg, R. 1996. Utility of NMR $\mathrm{T}_{2}$ distributions, connection with capillary pressure,

652 clay effect, and determination of the surface relaxivity parameter $\rho_{2}$. Magnetic resonance

653 imaging, 14, 761-767.

654 Kozeny, J. 1927. Ueber kapillare Leitung des Wassers im Boden.

655 Sitzungsber.Akad.Wiss.Wien, 136, 271-306.

656 Marschall, D., Gardner, J. S., Mardon, D. \& Coates, G. R. 1995. Method for correlating

657 NMR relaxometry and mercury injection data. Proceeding of the 1995 International

658 Symposium of Society of core Analysts, papers 9511.

659 Mortensen, J., Engstrøm, F. \& Lind, I. 1998. The relation among porosity, permeability,

660 and specific surface of chalk from the Gorm field, Danish North Sea. SPE Reservoir

661 Evaluation and Engineering, 1, 245-251. 
Hossain et al. Petrophysical properties of greensand as predicted from NMR

662 Ranganathan, V. \& Tye, R. S. 1986. Petrography, diagenesis, and facies controls on 663 porosity in Shannon Sandstone, Hartzog Draw Field, Wyoming. AAPG Bulletin, 70, 5666469.

665 Riepe, L. 1998. Specific internal surface: the “forgotten?” petrophysical measurement! 666 Proceeding of the 1998 International Symposium of Society of core Analysts, papers 6679540.

668 Rueslåtten, H., Eidesmo, T., Lehne, K. A. \& Relling, O. M. 1998. The use of NMR 669 spectroscopy to validate NMR logs from deeply buried reservoir sandstones. Journal of 670 Petroleum Science and Engineering, 19, 33-44.

671 Rueslåtten, H., Eidsemo, T. \& Slot-Petersen, C. 1998. NMR studies of iron-rich

672 sandstone oil reservoir. Proceeding of the 1998 International Symposium of Society of

673 core Analysts, papers 9821

674 Schiøler, P., Andsbjerg, J., Clausen, O. R., Dam, G., Dybkjær, K., Hamberg, L.,

675 Heilmann-Clausen, C., Johannessen, E. P., Kristensen, L. E. and Prince, I., 2007.

676 Lithostratigraphy of the Paleocene: Lower Neogene succession of the Danish North Sea.

677 Geological Survey of Denmark and Greenland, Danish Ministry of the Environment 678 report 77.

679 Slot-Petersen, C., Eidsemo, T., White, J. \& Rueslatten, H. G. 1998. NMR formation 680 evaluation application in a complex low resistivity hydrocarbon reservoir. Transactions 681 of the SPWLA 39th Annual Logging Symposium, Paper 1998-TT 
Hossain et al. Petrophysical properties of greensand as predicted from NMR

682 Solymar, M. \& Fabricius, I. L. 1999. Image analysis and estimation of porosity and 683 permeability of Arnager Greensand, Upper Cretaceous, Denmark. Physics and Chemistry 684 of the Earth Part A-Solid Earth and Geodesy, 24, 587-591.

685 Solymar, M., Fabricius, I. L. \& Middleton, M. 2003. Flow characterization of glauconitic 686 sandstones by integrated Dynamic Neutron Radiography and image analysis of 687 backscattered electron micrographs. Petroleum Geoscience, 9, 175-183.

688 Stokkendal, J., Friis, H., Svendsen, J. B., Poulsen, M. L. K. \& Hamberg, L. 2009.

689 Predictive permeability variations in a Hermod sand reservoir, Stine Segments, Siri Field, 690 Danish North Sea. Marine and Petroleum Geology, 26, 397-415.

691 Straley, C., Roosini, D., Vinegar, H., Tutunjian, P. \& Morriss, C. 1997. Core analysis by 692 low-field NMR. The Log Analyst, 38, 84-94.

693 Tilley, B. J. \& Longstaffe, F. J. 1984. Controls on hydrocarbon accumulation in 694 glauconitic sandstone, Suffield heavy oil sands, southern Alberta. AAPG Bulletin, 68, $695 \quad 1004-1023$.

696 Underwood, E. E. 1970. Quantitative stereology. Addison -Wesley, Reading, 697 Massachusetts, 270.

698 Volokitin, Y., Looyestijn, W. J., Slijkerman, W. F. J. \& Hofman, J. P. 1999. A Practical 699 Approach to Obtain 1st Drainage Capillary Pressure Curves From NMR Core and Log 700 Data. The International Symposium of the Society of Core Analysts, 24, 1-4. 
701 Winn, R. D. 1994. Shelf Sheet-Sand Reservoir of the Lower Cretaceous Greensand,

702 North Celtic Sea Basin, Offshore Ireland. AAPG Bulletin, 78, 1775-1789.

703 Xie, R. H., Xiao, L. Z., Wang, Z. D. \& Dunn, K. J. 2008. The influence factors of NMR

704 logging porosity in complex fluid reservoir. Science in China Series D: Earth Sciences,

705 51, 212-217.

706 
Hossain et al. Petrophysical properties of greensand as predicted from NMR

\section{Figure captions}

708

709 Fig. 1. BSE images of greensand samples. (a) Sample 1-4 from Hermod Formation and

710 (b) sample 1A-142 from Ty Formation. Scale bar is $200 \mu \mathrm{m}$. Q: quartz; Gl: glauconite; H:

711 Heavy minerals, M: Mica; PF: pore filling clay minerals. Porosity, permeability and

712 irreducible water saturation are 37 p.u., $530 \mathrm{mD}$ and $26 \%$ for sample 1-4 and 29 p.u., 150

$713 \mathrm{mD}$ and $38 \%$ for sample 1A-142.

714

715 Fig. 2. Location map showing the position of the Nini-1 well used in this study (arrow).

716 The margins of the Siri Canyon are shown by grey shading. An area of positive relief

717 within the canyon is also shown by grey shading. G, Germany; N, Norway; NL,

718 Netherlands; S, Sweden; UK, United Kingdom (Figure modified after Schiøler et al.

719 2007).

720

721 Fig. 3. Gamma ray, porosity and resistivity logs for wells Nini-1 (top) and Nini-1A

722 (bottom). The glauconite bearing reservoir intervals (Hermod sand and Ty sand) have

723 relatively low separation between neutron- and density porosity. Horizontal dashed lines

724 indicate the studied core intervals. Core data are shown for reference. Permeability is

725 higher in Hermod sand than in Ty sand.

726

727 Fig. 4: Macro-porosity and micro-porosity determination for sample 1-4 (a) from NMR

$728 \quad T_{2}$ distribution (b) from the capillary pressure curve. The cumulative distribution for the

729 fully saturated sample is compared to the cumulative distribution after centrifuging at 100 
Hossain et al. Petrophysical properties of greensand as predicted from NMR

730 psi. The cutoff time which separates the $\mathrm{T}_{2}$ distribution into macro-porosity and micro-

731 porosity is defined as the relaxation time at the point where the cumulative porosity of the

732 fully saturated sample equals the irreducible water saturation. The dashed vertical line is

733 shown a cutoff of $5.21 \mathrm{~ms}$. The capillary pressure of 100 psi corresponds to a micro-

734 porosity of $9.1 \%$.

735

736 Fig. 5. Cross plot of macro-porosity from capillary pressure measurement and

737 permeability. Samples from the Hermod sand have similar porosity and permeability,

738 whereas the samples from Ty sand are more scattered. The reference lines represent equal

739 specific surface of pores (Sp (Kozeny)) in $\mu \mathrm{m}^{-1}$ as calculated by using Kozeny's equation.

740 The data indicate that $S p$ is lower in Hermod sand than in Ty sand.

742 Fig. 6. Bulk composition of investigated samples from Hermod and Ty Formations of the

743 Nini Field. Mineral composition was determined by point counting of 500 points across

744 each entire thin-section. Macro-porosity was determined by image analysis when porosity

745 threshold is equal to macro-porosity determined from $\mathrm{P}_{\mathrm{C}}$ measurements. Micro-porosity is

746 the difference between Helium porosity and image porosity.

748 Fig. 7. (a), (c) Capillary pressure curves and (b), (d) NMR $\mathrm{T}_{2}$ distribution curves of

749 greensand samples. (a) $\mathrm{P}_{\mathrm{c}}$ curves of Hermod Formation samples are shifted toward low

750 irreducible water saturation, whereas (c) the Ty Formation samples have relatively high

751 irreducible water saturation. This pattern compares to the relatively high permeability of

752 Hermod sand relative to the low permeability of Ty sand (Fig. 3). $T_{2}$ distribution of all 
Hossain et al. Petrophysical properties of greensand as predicted from NMR

753 samples shows two peaks. The peak close to $1 \mathrm{~ms}$ represents micro-porosity and the peak

754 close to 100 ms represents macro-porosity.

755

756 Fig. 8. (a) Helium porosity, Archimedes porosity and NMR porosity of investigated

757 samples. Helium porosity tends to be the highest, whereas NMR porosity is

758 underestimated due to iron bearing minerals in greensand. (b) Cross plot of delta porosity

759 (Archimedes porosity-NMR porosity) and minerals bulk composition (glauconite, pore

760 filling clay and clay coating). Cross plots of (c) macro-porosity and (d) micro-porosity

761 from NMR $\mathrm{T}_{2}$ distribution and capillary pressure curves.

762

763 Fig. 9. Correlation between specific surface of pores as measured by BET (Sp (BET)) and

764 (a) irreducible water saturation as determined from NMR measurements, (b) irreducible

765 water saturation as determined from capillary pressure measure as well as (c) clay

766 minerals (glauconite, clay coating and pore filling clay) as percentage of bulk

767 composition.

768

769 Fig. 10. (a) Specific surface area with respect to pore (Sp) determined by BET nitrogen

770 adsorption (Sp (BET)), estimated from Kozeny’s equation (Sp (Kozeny)) and determined

771 by image analysis of the BSE images (Sp (image)). (b) Surface relaxivity determined

772 comparing $\mathrm{T}_{2}$ distribution with Sp (BET), Sp (Kozeny), and Sp (image). For two samples,

773 surface relaxivity are also determined from capillary pressure versus NMR $\mathrm{T}_{2}$

774 distribution.

775 
Hossain et al. Petrophysical properties of greensand as predicted from NMR

776 Fig. 11. (a), (b) Porosity distribution and cumulative porosity for five greensand samples.

777 (c), (d) Permeability distribution of five greensand samples obtained from Kozeny's

778 equation.

779

780 Fig. 12. Measured permeability versus NMR predicted permeability by using surface

781 relaxivity from (a) $S p$ (Kozeny), (b) $S p$ (image), (c) $S p\left(B E T\right.$ ), (d) $\mathrm{P}_{\mathrm{c}}$ versus NMR and (e)

782 from Timur-Coates model. (g) Measured permeability versus predicted permeability from

783 image analysis. Image permeability and NMR predicted permeability by using surface

784 relaxivity from Sp(image) are equal.

785

786 Fig. 13. Air Brine capillary pressure curves including saturation error compared with

787 NMR derived capillary pressure including saturation error. Saturation error corresponds

788 to the error associated with porosity measurements. The NMR derived capillary pressure

789 curves are based on surface relaxivity value of $20.4 \mu \mathrm{m} / \mathrm{s}$ for Hermod Formation and 28.4

$790 \mu \mathrm{m} / \mathrm{s}$ for Ty formation. Deviation between average surface relaxivity (solid line) and

791 surface relaxivity for predicting $\mathrm{P}_{\mathrm{c}}$ NMR (dashes line) are shown (e) for Hermod

792 Formation and (f) for Ty Formation.

793 
Hossain et al. Petrophysical properties of greensand as predicted from NMR

\section{List of tables}

795

796 Table 1. Core plug porosity data. Helium porosity was measured by Helium gas

797 expansion, Archimedes porosity was measured by immersing, and NMR porosity was

798 measured by the signal amplitude of $T_{2}$ measurements respectively. Archimedes macro-

799 porosity and NMR macro-porosity were determined from capillary pressure curves and

$800 \quad T_{2}$ distributions respectively.

801

802 Table 2. Core plug data. Specific surface area of grains (SSA) was measured by BET

803 method and effective specific surface of pores (Sp(Kozeny)) was calculated by using

804 Kozeny’s equation. Image specific perimeter of pores (Sp(image)) was determined by

805 image analysis by using the method of Borre et al. (1997). The cutoff time which

806 separates the $T_{2}$ distribution into macro-porosity and micro-porosity is defined as the

807 relaxation time at the point where the cumulative porosity of the fully saturated sample

808 equals the irreducible water saturation. 
Fig. 1
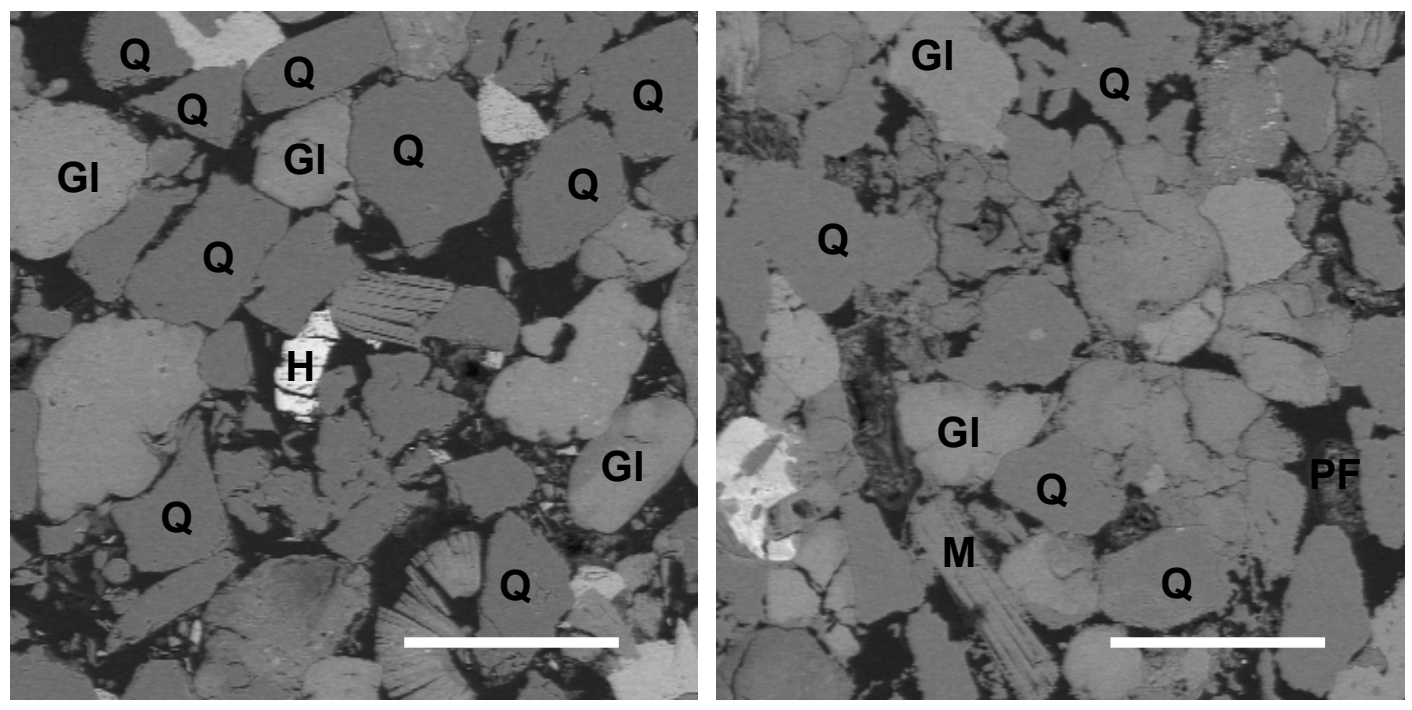

(a)

(b) 
Hossain et al. Figures

Fig. 2

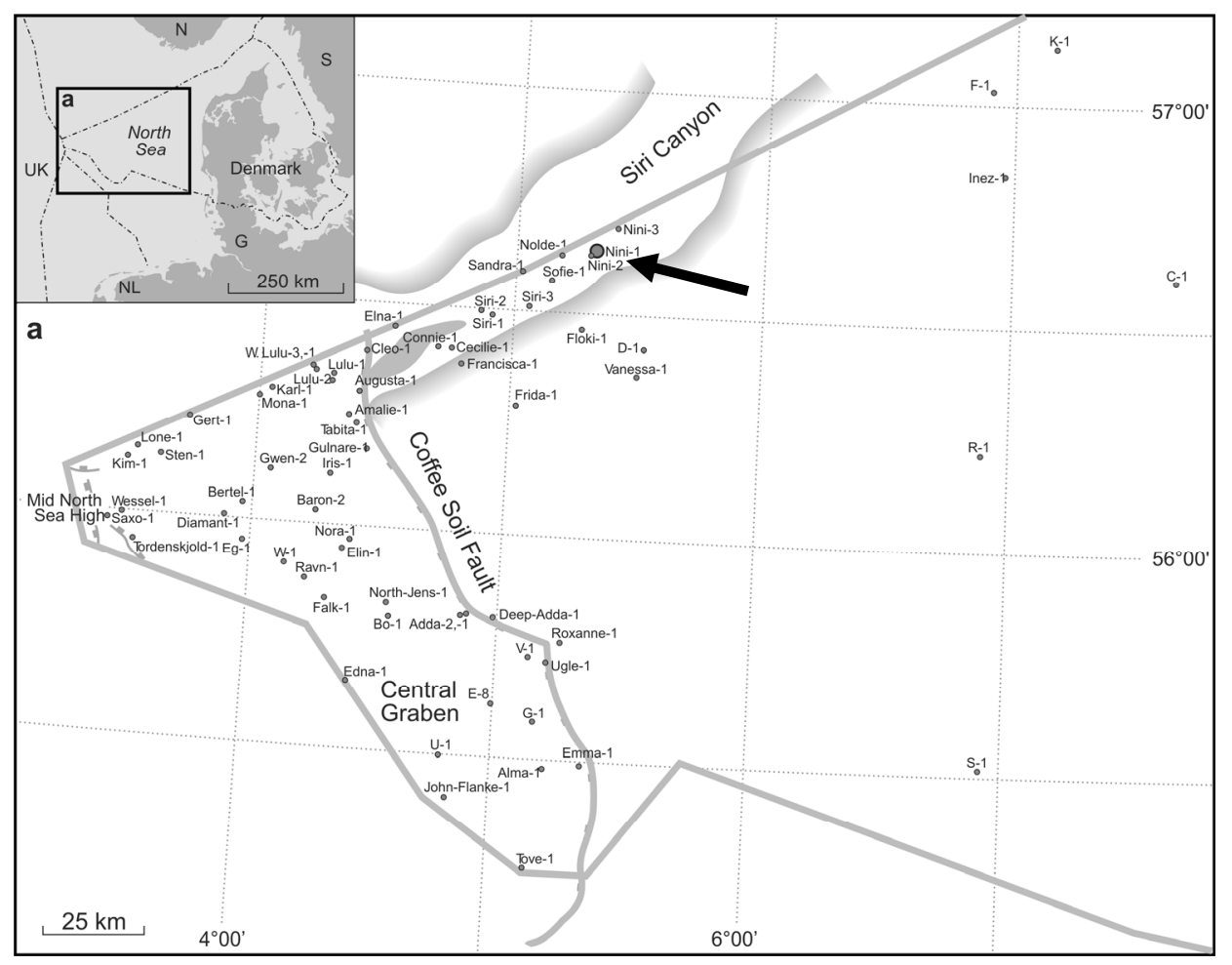


Hossain et al. Figures

Fig. 3

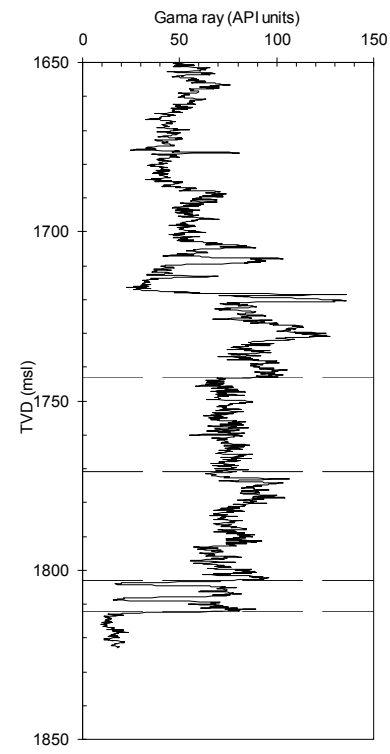

(a)

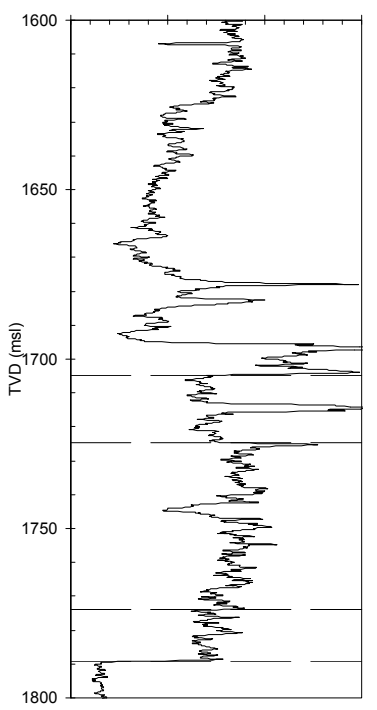

(e)

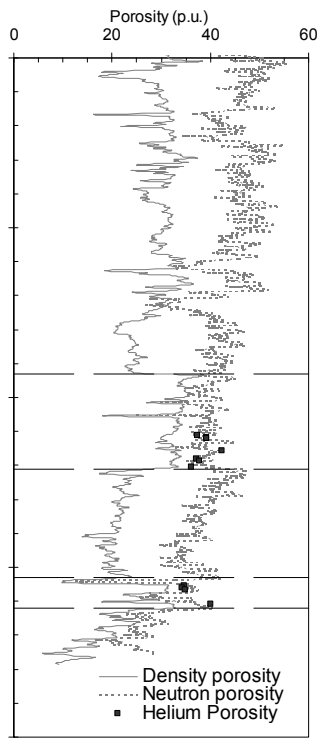

(b)

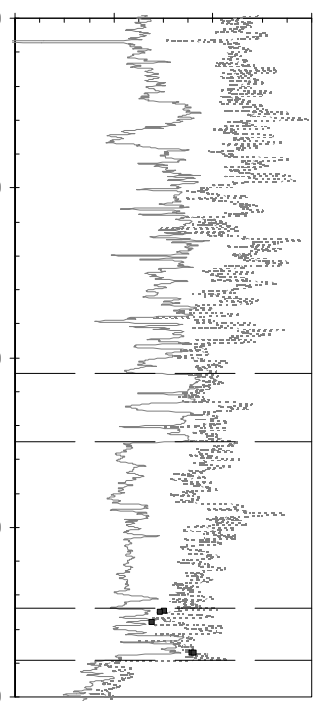

(f)

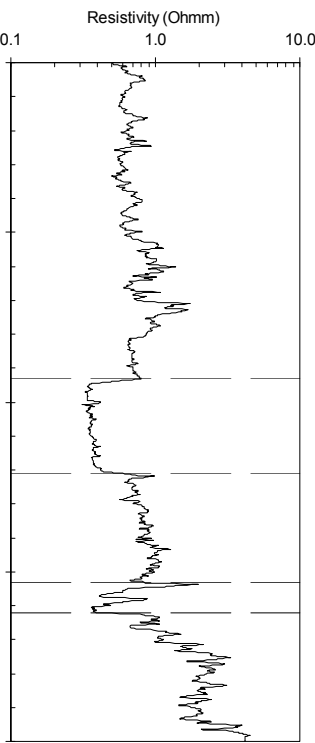

(c)

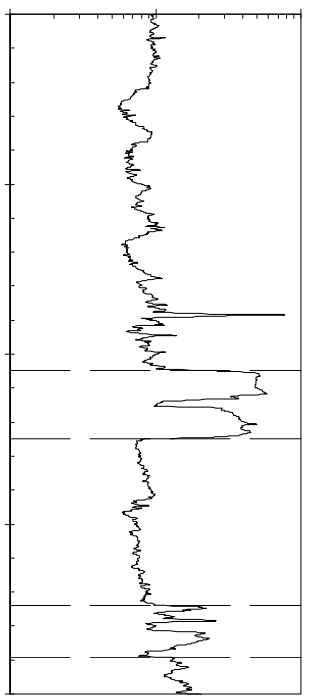

(g)

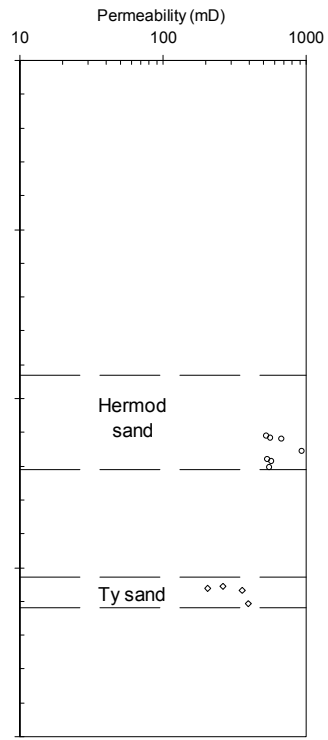

(d)

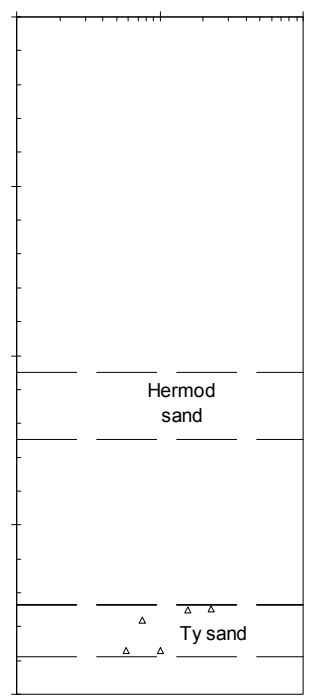

(h) 
Hossain et al. Figures

Fig. 4
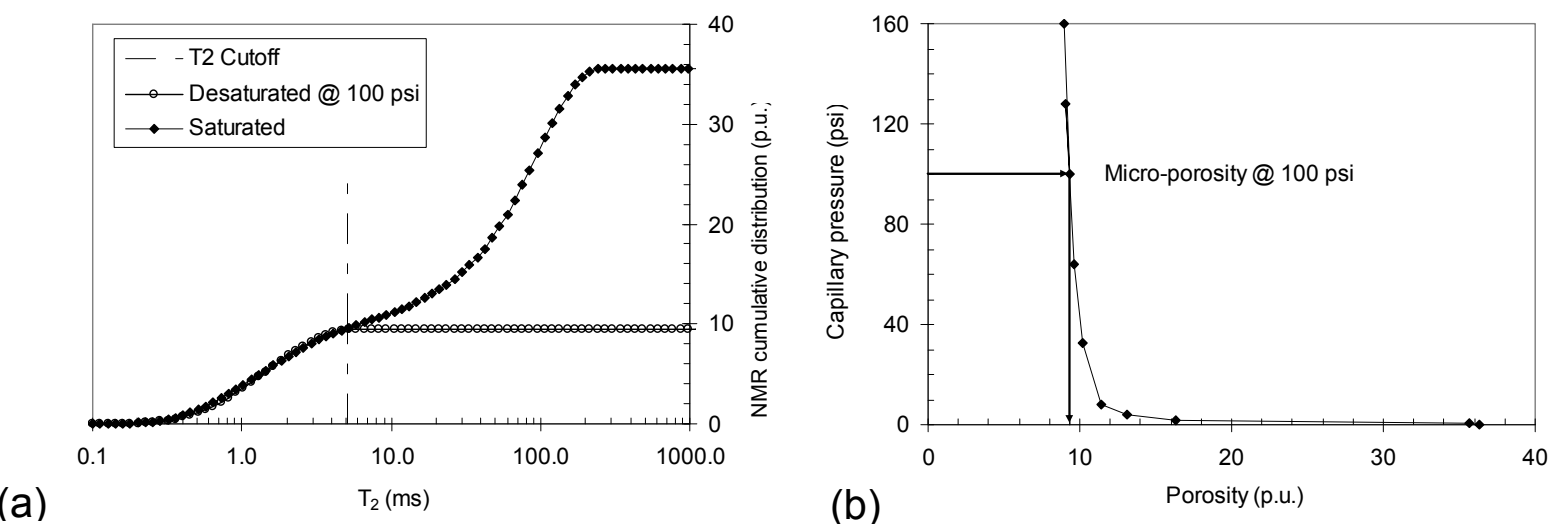
Fig. 5

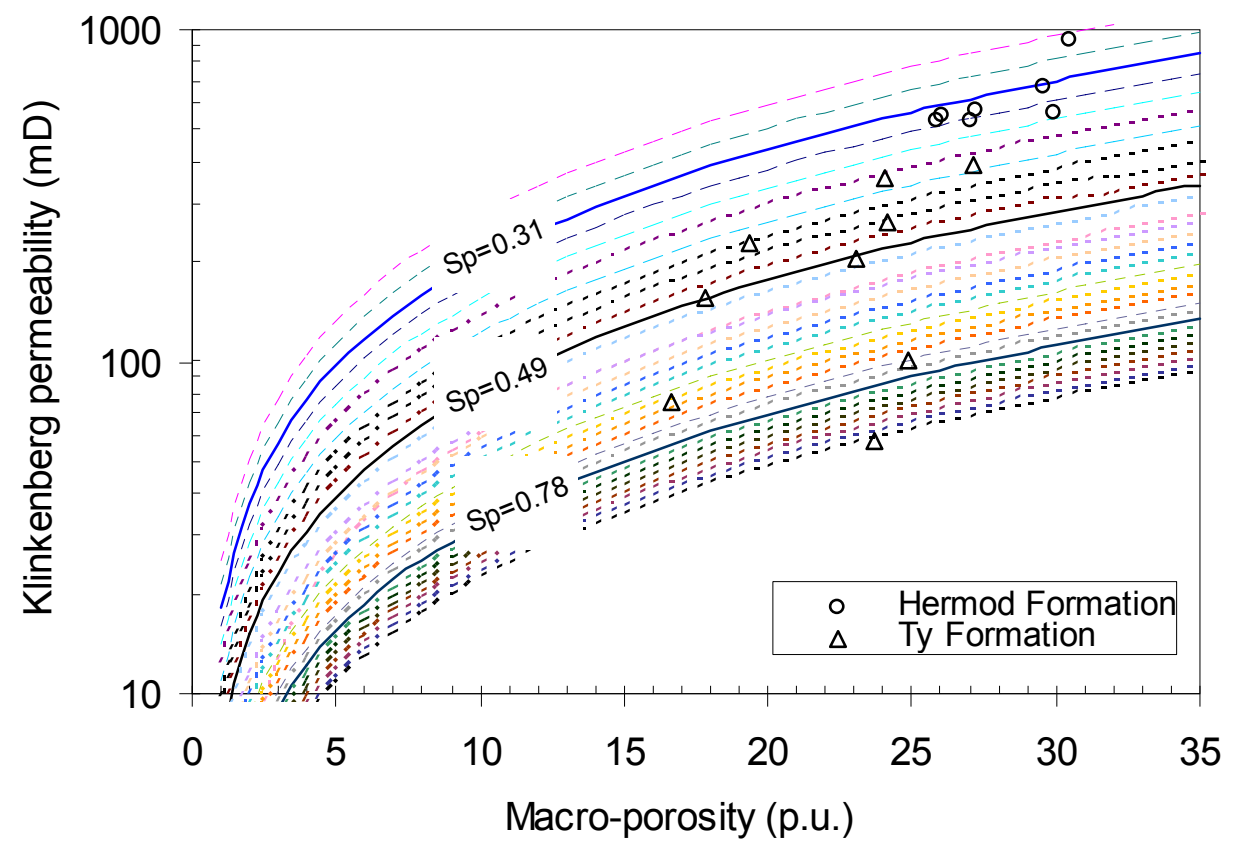


Fig. 6

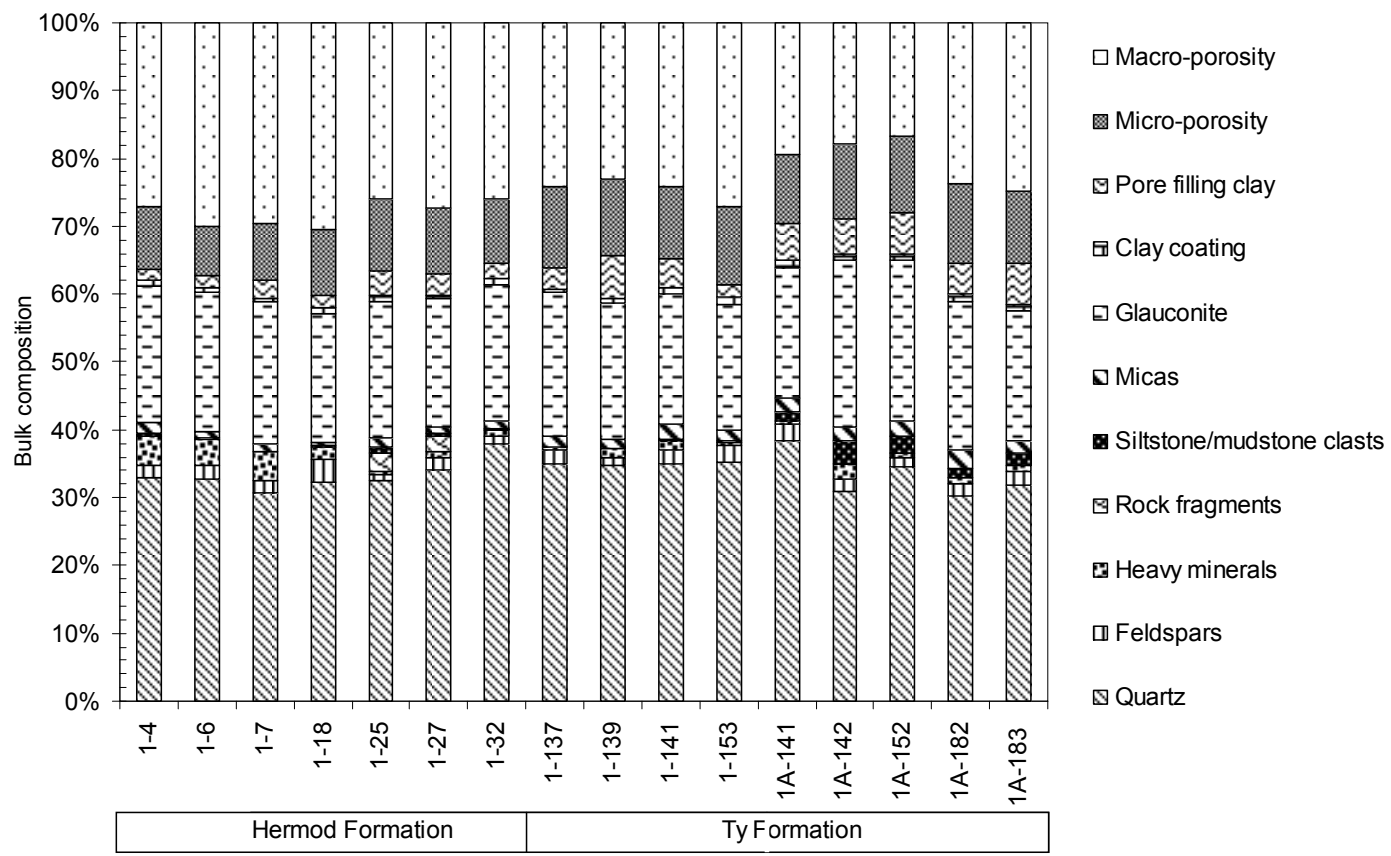


Hossain et al. Figures

\section{Fig. 7}

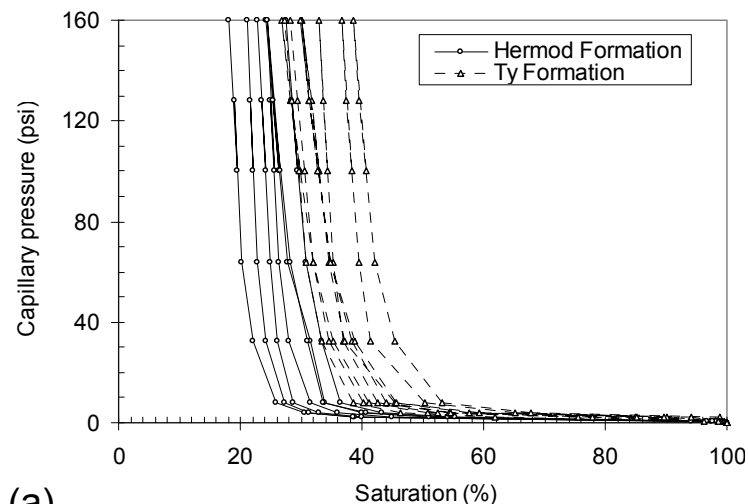

(a)
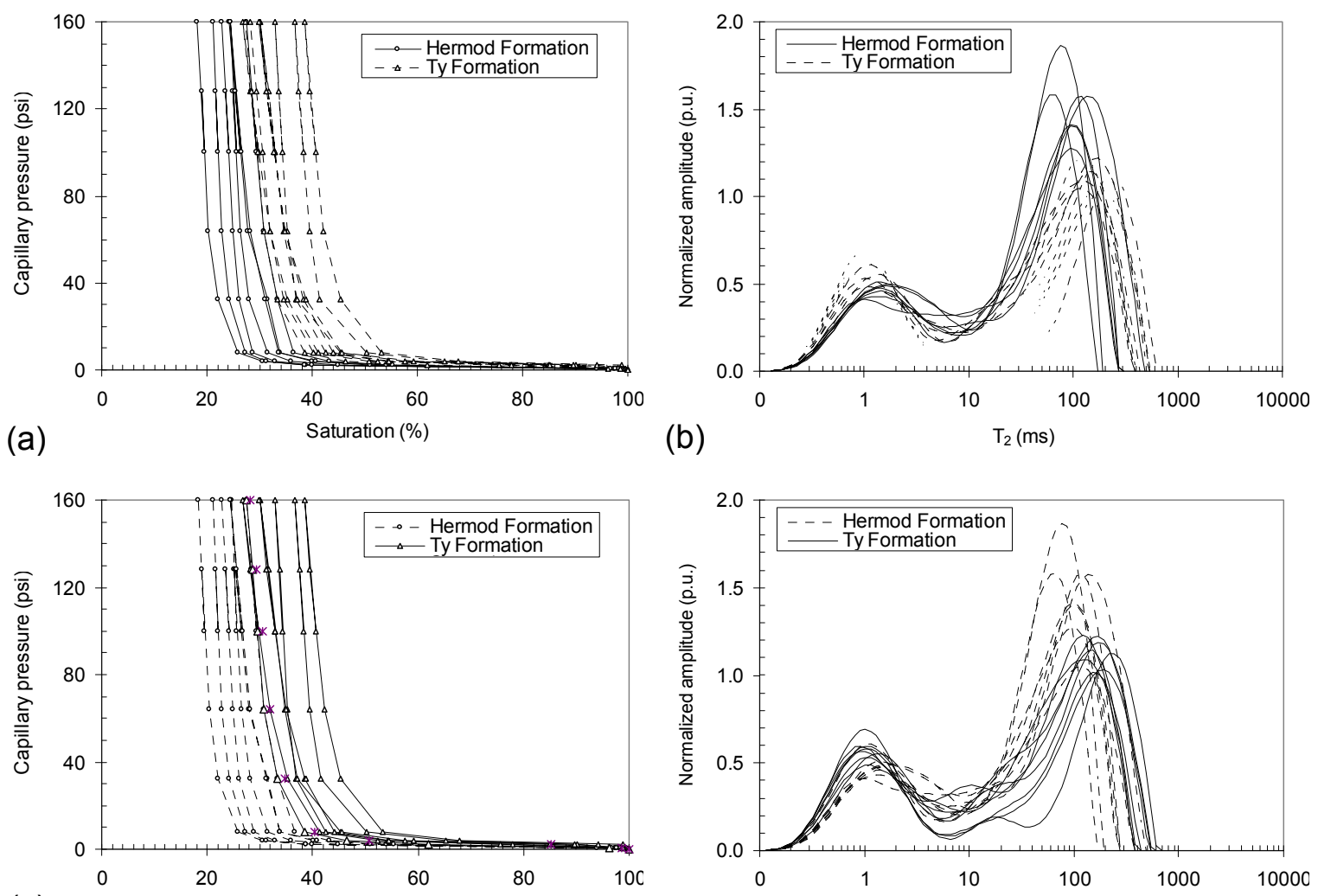

(c)

Saturation (\%)

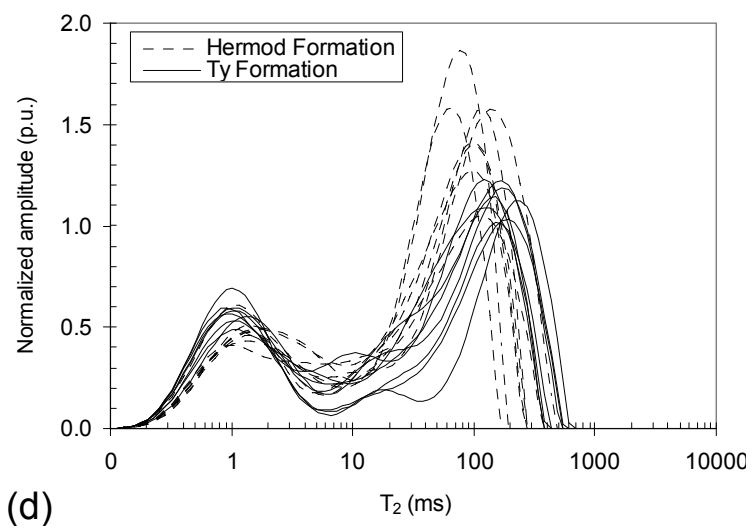


Fig. 8
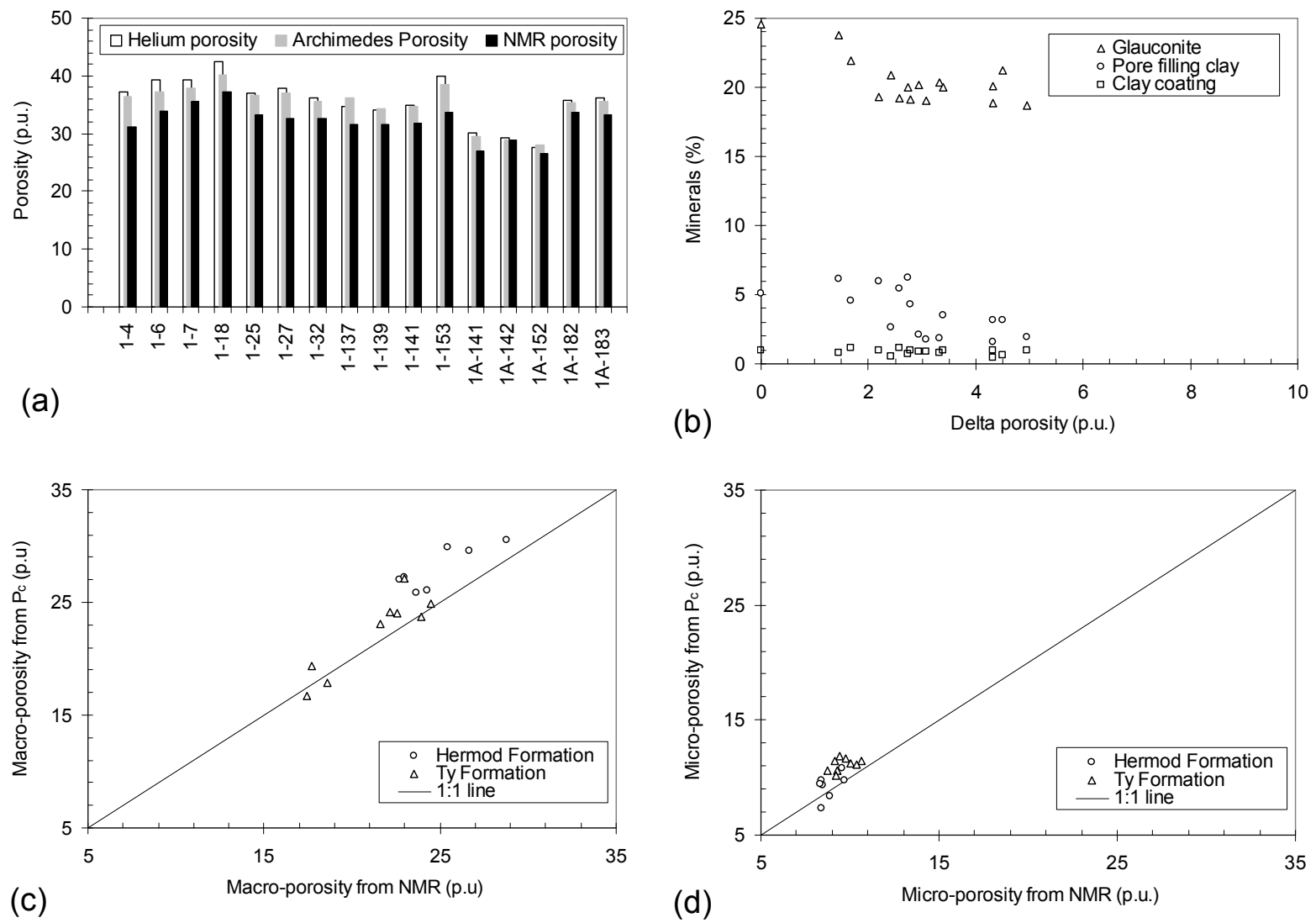
Hossain et al. Figures

Fig. 9
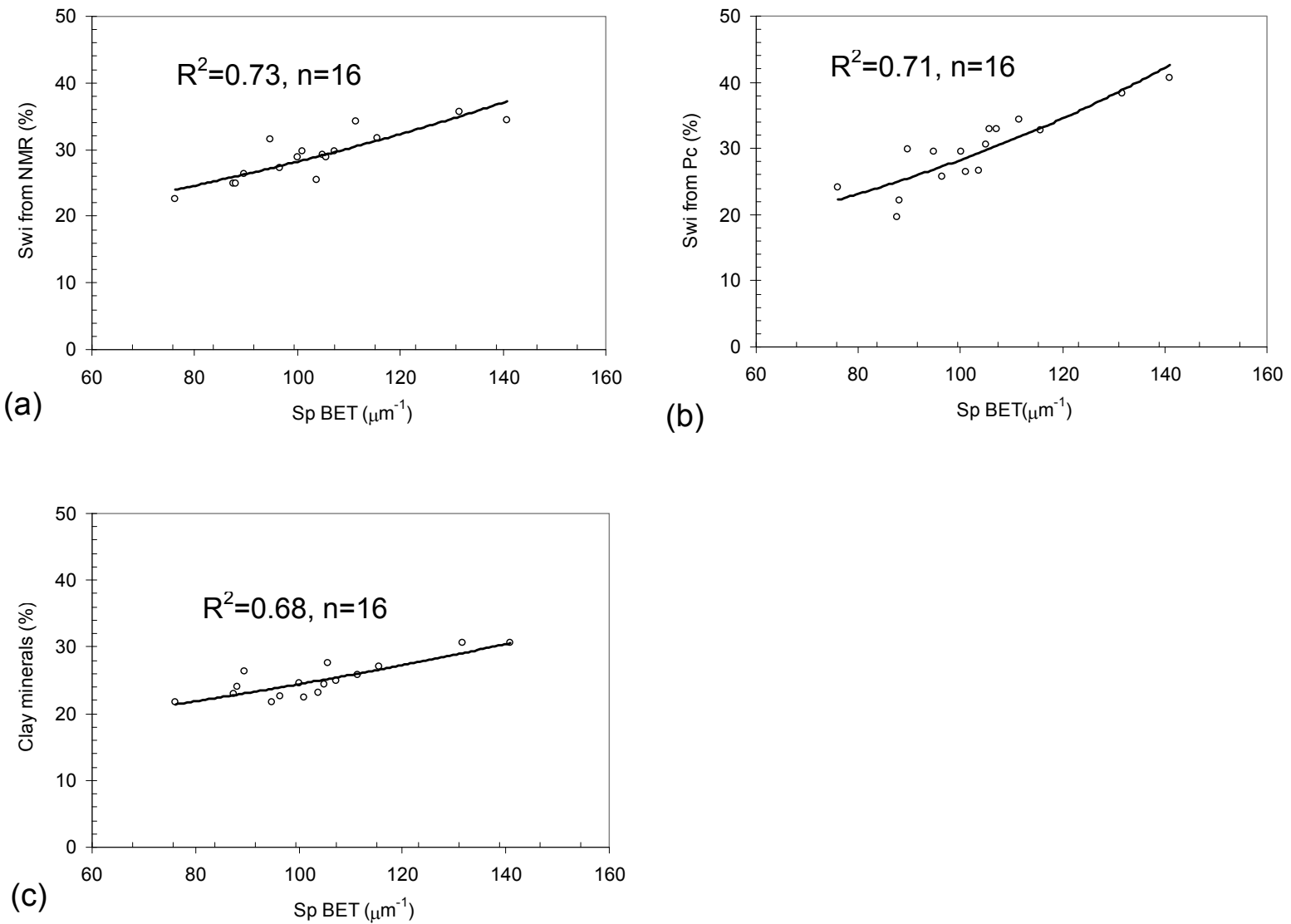
Fig. 10
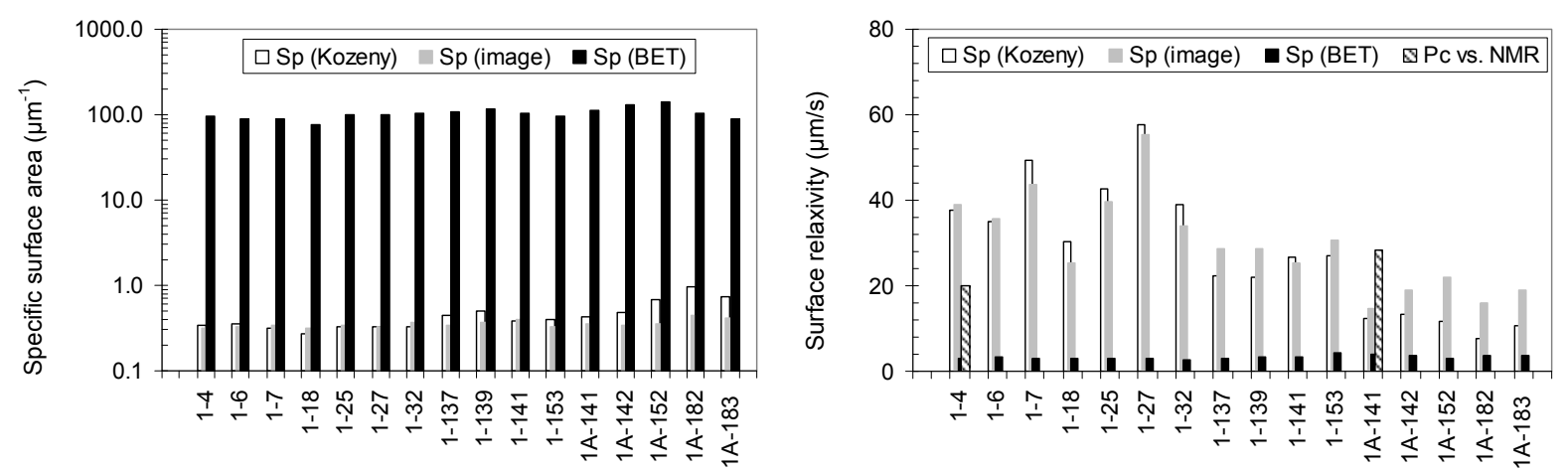

(a)

(b) 
Fig. 11
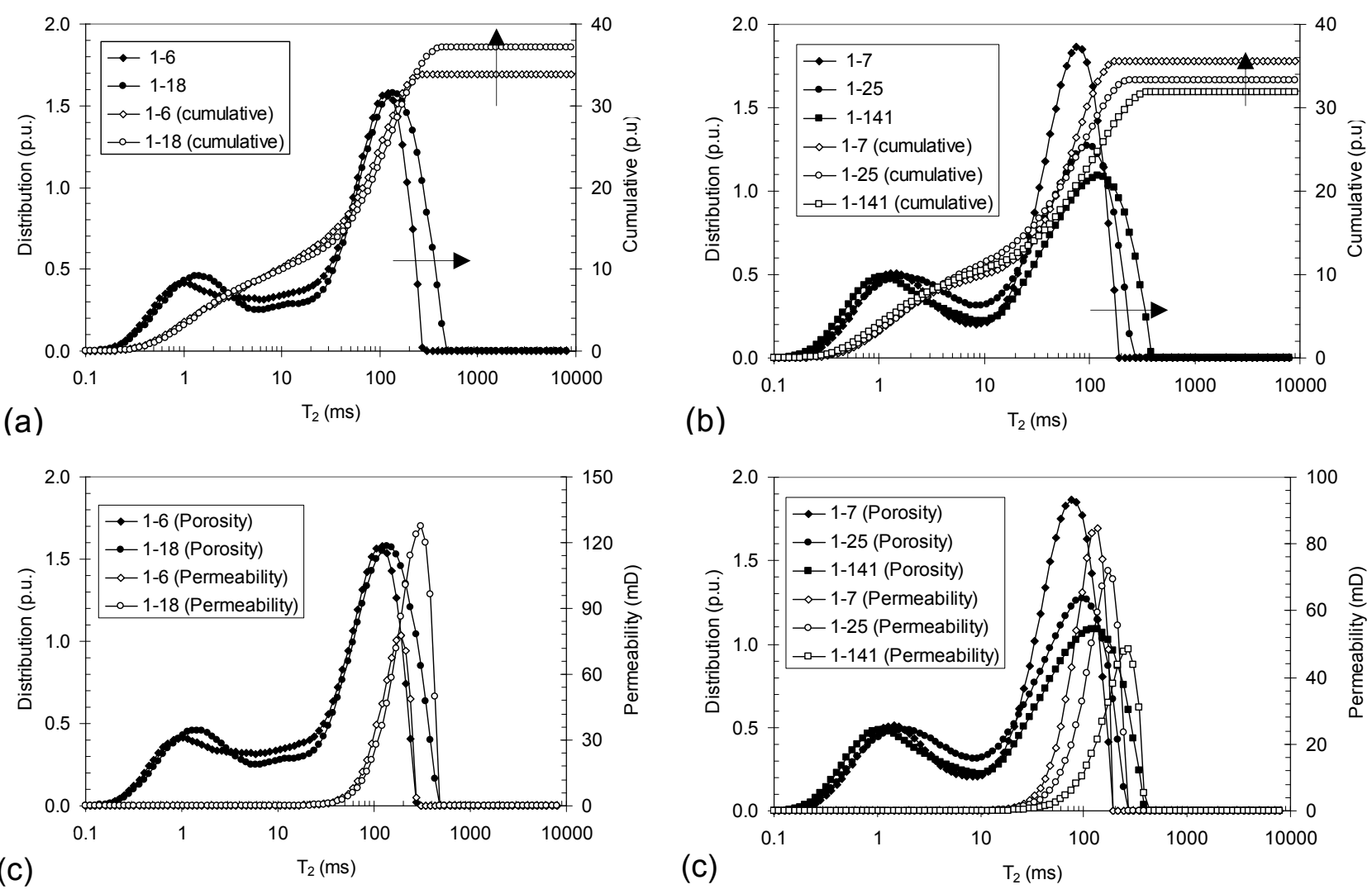
Fig. 12
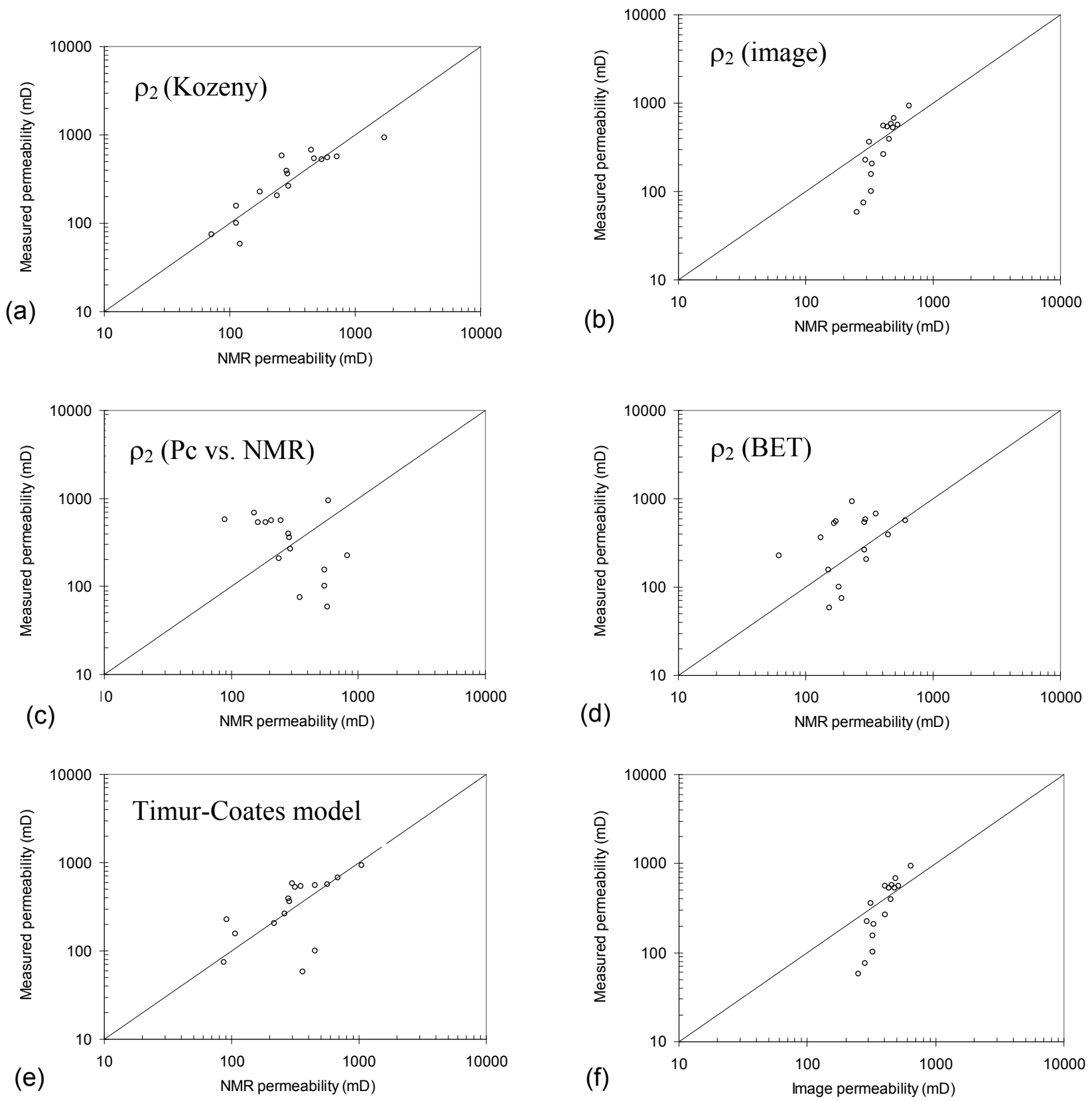
Fig. 13
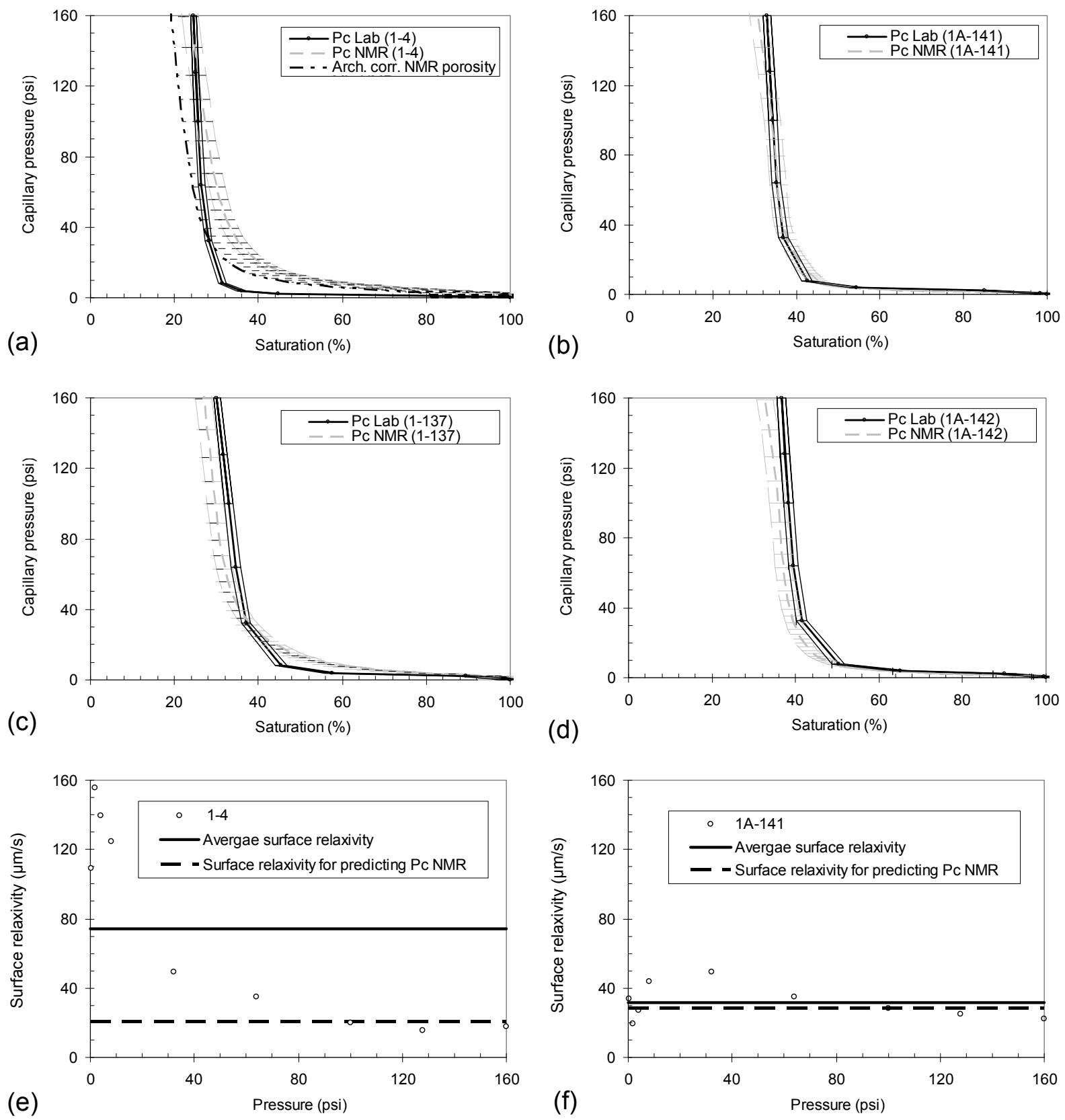
Hossain et al. Tables

Table 1

\begin{tabular}{|c|c|c|c|c|c|c|c|c|c|c|c|}
\hline \multirow{2}{*}{$\begin{array}{l}\text { Formation } \\
\text { Hermod }\end{array}$} & \multirow{2}{*}{$\begin{array}{c}\begin{array}{c}\text { Measured } \\
\text { Depth } \\
(\mathrm{m})\end{array} \\
1761.1\end{array}$} & \multirow[t]{2}{*}{$\begin{array}{l}\text { TVD } \\
(\mathrm{msl})\end{array}$} & \multirow{2}{*}{$\begin{array}{l}\begin{array}{l}\text { Sample } \\
\text { ID }\end{array} \\
1-4\end{array}$} & \multicolumn{2}{|c|}{$\begin{array}{l}\text { Helium porosity } \\
\text { (p.u.) } \\
\text { Error } \pm\end{array}$} & \multicolumn{2}{|c|}{$\begin{array}{r}\text { Archimedes } \\
\text { porosity (p.u.) } \\
\text { Error } \pm\end{array}$} & \multicolumn{2}{|c|}{$\begin{array}{l}\text { NMR porosity } \\
\text { (p.u.) } \\
\text { Error } \pm\end{array}$} & \multirow{2}{*}{$\begin{array}{c}\text { Archimedes } \\
\text { macro- } \\
\text { porosity } \\
\text { (p.u.) } \\
27.0\end{array}$} & \multirow{2}{*}{$\begin{array}{c}\text { NMR } \\
\text { macro- } \\
\text { porosity } \\
\text { (p.u.) } \\
22.7\end{array}$} \\
\hline & & & & 37.3 & 1.5 & 35.5 & 1.1 & 31.2 & 0.4 & & \\
\hline & 1761.7 & & 1-6 & 39.3 & 1.3 & 37.2 & 1.1 & 33.8 & 0.5 & 29.9 & 25.4 \\
\hline & 1762.1 & & $1-7$ & 39.2 & 0.4 & 37.9 & 1.1 & 35.5 & 0.5 & 29.6 & 26.7 \\
\hline & 1765.7 & & $1-18$ & 42.4 & 0.5 & 40.2 & 1.2 & 37.2 & 0.5 & 30.5 & 28.8 \\
\hline & 1768.1 & & $1-25$ & 37.1 & 0.5 & 36.7 & 1.1 & 33.3 & 0.5 & 25.9 & 23.7 \\
\hline & 1768.7 & & $1-27$ & 37.8 & 1.1 & 37.0 & 1.1 & 32.7 & 0.5 & 27.2 & 23.0 \\
\hline & 1770.4 & & $1-32$ & 36.2 & 0.9 & 35.5 & 1.1 & 32.6 & 0.5 & 26.0 & 24.3 \\
\hline \multirow[t]{9}{*}{ Ty } & 1805.5 & & $1-137$ & 34.7 & 0.8 & 36.1 & 1.1 & 31.6 & 0.4 & 24.2 & 22.2 \\
\hline & 1806.1 & & $1-139$ & 34.2 & 0.5 & 34.3 & 1.0 & 31.6 & 0.4 & 23.1 & 21.6 \\
\hline & 1806.7 & & $1-141$ & 34.9 & 0.3 & 34.6 & 1.0 & 31.8 & 0.4 & 24.1 & 22.5 \\
\hline & 1810.7 & & $1-153$ & 40.0 & 0.4 & 38.6 & 1.2 & 33.6 & 0.5 & 27.2 & 23.0 \\
\hline & 1972.1 & 1774.7 & $1 A-141$ & 30.1 & 0.1 & 29.5 & 0.9 & 27.0 & 0.4 & 19.4 & 17.7 \\
\hline & 1972.4 & 1775.0 & $1 A-142$ & 29.3 & 0.7 & 29.0 & 0.9 & 29.0 & 0.4 & 17.9 & 18.6 \\
\hline & 1975.8 & 1778.1 & $1 A-152$ & 27.7 & 0.3 & 28.1 & 0.8 & 26.6 & 0.4 & 16.7 & 17.5 \\
\hline & 1985.7 & 1787.0 & $1 A-182$ & 35.7 & 0.1 & 35.3 & 1.1 & 33.7 & 0.5 & 23.7 & 23.9 \\
\hline & 1986.0 & 1787.2 & $1 A-183$ & 36.2 & 0.4 & 35.5 & 1.1 & 33.3 & 0.5 & 24.9 & 24.5 \\
\hline
\end{tabular}


Table 2

\begin{tabular}{|c|c|c|c|c|c|c|c|}
\hline $\begin{array}{c}\text { Sample } \\
\text { ID }\end{array}$ & $\begin{array}{c}\text { Klinkenberg } \\
\text { permeability } \\
(\mathrm{mD})\end{array}$ & $\begin{array}{c}\text { SSA } \\
(B E T) \\
\left(\mathrm{m}^{2} / \mathrm{g}\right)\end{array}$ & $\begin{array}{c}\text { Sp } \\
\text { (Kozeny) } \\
\left(\mu \mathrm{m}^{-1}\right)\end{array}$ & $\begin{array}{c}\mathrm{Sp} \\
\text { (image) } \\
\left(\mu \mathrm{m}^{-1}\right)\end{array}$ & $\begin{array}{c}\mathrm{T}_{2} \text { Cutoff } \\
\text { (ms) }\end{array}$ & $\begin{array}{c}\text { Irreducible } \\
\text { water } \\
\text { saturation } \\
\text { from } \mathrm{P}_{\mathrm{c}}(\%)\end{array}$ & $\begin{array}{c}\text { Irreducible } \\
\text { water } \\
\text { saturation } \\
\text { from NMR (\%) }\end{array}$ \\
\hline $1-4$ & 530 & 21 & 0.34 & 0.32 & 5.2 & 25.6 & 27.2 \\
\hline $1-6$ & 560 & 21 & 0.35 & 0.33 & & 19.6 & 24.9 \\
\hline $1-7$ & 680 & 21 & 0.31 & 0.35 & & 22.1 & 24.9 \\
\hline $1-18$ & 940 & 19 & 0.27 & 0.32 & & 24.2 & 22.6 \\
\hline $1-25$ & 540 & 20 & 0.33 & 0.35 & & 29.4 & 28.8 \\
\hline $1-27$ & 570 & 22 & 0.33 & 0.33 & & 26.5 & 29.8 \\
\hline $1-32$ & 550 & 21 & 0.32 & 0.36 & & 26.7 & 25.5 \\
\hline $1-137$ & 260 & 20 & 0.45 & 0.34 & & 33.0 & 29.8 \\
\hline $1-139$ & 210 & 22 & 0.49 & 0.38 & & 32.8 & 31.8 \\
\hline $1-141$ & 360 & 20 & 0.38 & 0.39 & & 30.5 & 29.2 \\
\hline $1-153$ & 390 & 23 & 0.39 & 0.33 & & 29.6 & 31.6 \\
\hline $1 \mathrm{~A}-141$ & 230 & 17 & 0.43 & 0.35 & 3.7 & 34.4 & 34.2 \\
\hline $1 \mathrm{~A}-142$ & 160 & 19 & 0.49 & 0.35 & & 38.4 & 35.7 \\
\hline $1 \mathrm{~A}-152$ & 80 & 20 & 0.68 & 0.36 & & 40.7 & 34.4 \\
\hline $1 \mathrm{~A}-182$ & 60 & 22 & 0.95 & 0.46 & & 32.9 & 28.9 \\
\hline $1 \mathrm{~A}-183$ & 100 & 19 & 0.74 & 0.41 & & 29.9 & 26.4 \\
\hline
\end{tabular}

